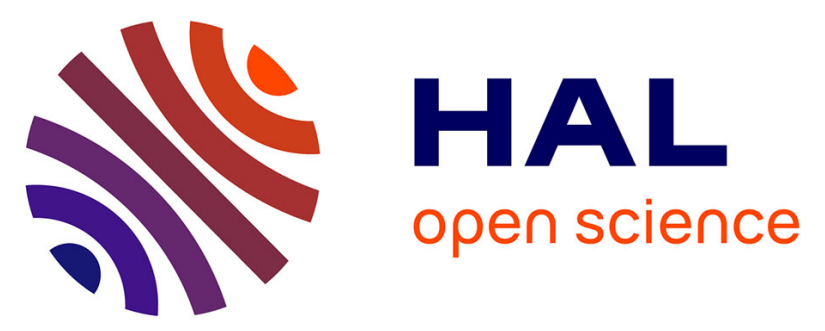

\title{
Cutaneous Squamous Cell Carcinoma Development Is Associated with a Temporal Infiltration of ILC1 and NK Cells with Immune Dysfunctions
}

Carmelo Luci, Franck Bihl, Pierre Bourdely, Sokchea Khou, Alexandra Popa, Aida Meghraoui-Kheddar, Ophelie Vermeulen, Roxane Elaldi, Gilles

Poissonnet, Anne Sudaka, et al.

\section{To cite this version:}

Carmelo Luci, Franck Bihl, Pierre Bourdely, Sokchea Khou, Alexandra Popa, et al.. Cutaneous Squamous Cell Carcinoma Development Is Associated with a Temporal Infiltration of ILC1 and NK Cells with Immune Dysfunctions. Journal of Investigative Dermatology, 2021, 141 (10), pp.2369-2379. 10.1016/j.jid.2021.03.018 . hal-03368175

\section{HAL Id: hal-03368175 https://hal.science/hal-03368175}

Submitted on 8 Oct 2021

HAL is a multi-disciplinary open access archive for the deposit and dissemination of scientific research documents, whether they are published or not. The documents may come from teaching and research institutions in France or abroad, or from public or private research centers.
L'archive ouverte pluridisciplinaire HAL, est destinée au dépôt et à la diffusion de documents scientifiques de niveau recherche, publiés ou non, émanant des établissements d'enseignement et de recherche français ou étrangers, des laboratoires publics ou privés. 
DMBA/PMA induced skin carcinogenesis
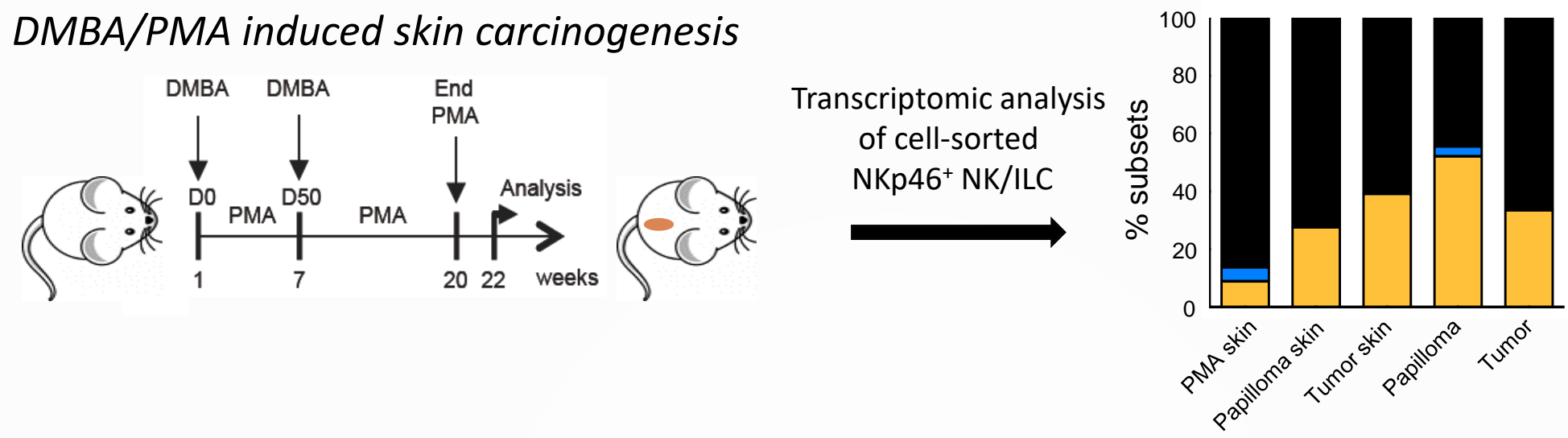

\section{Surrounding skin

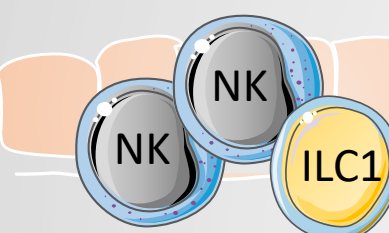 \\ IFN- $\gamma$ TNF- $\alpha$ IFN- $\gamma$}

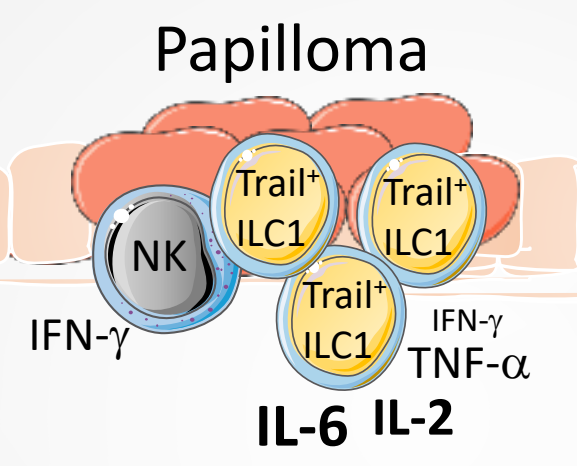

Tumor

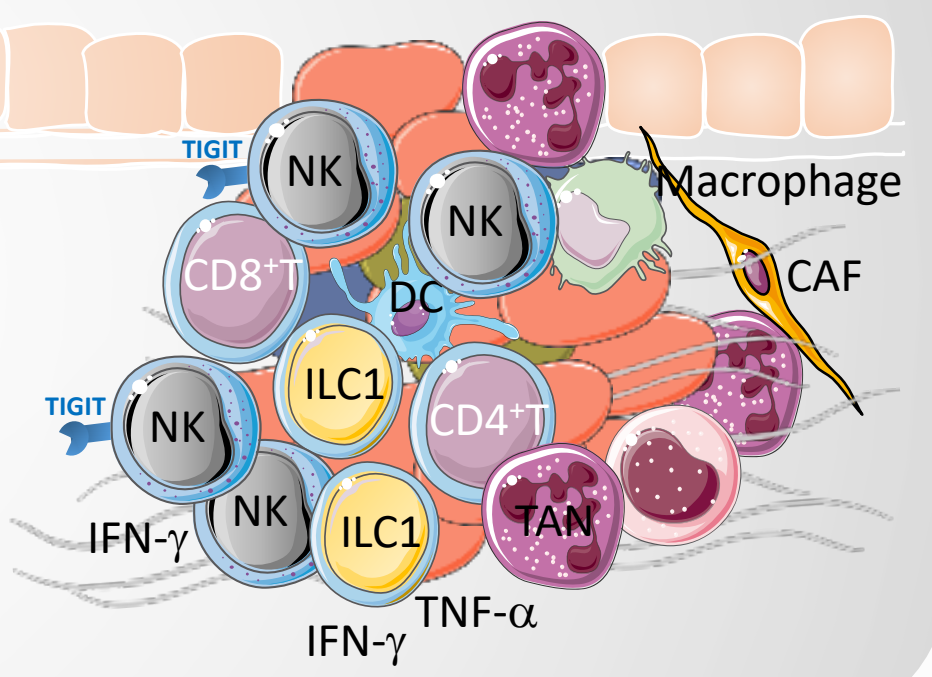




\section{Cutaneous Squamous Cell Carcinoma Development is Associated with a Temporal Infiltration of ILC1 and NK Cells with Immune Dysfunctions}

Luci $\mathrm{C}^{1, \mathrm{a}, *}$, , Bihl $\mathrm{F}^{1, *}$, Bourdely $\mathrm{P}^{1, \mathrm{~b}}$, Khou $\mathrm{S}^{1 \mathrm{c}}$, Popa $\mathrm{A}^{1, \mathrm{~d}}$, Meghraoui-Kheddar $\mathrm{A}^{1}$, Vermeulen $\mathrm{O}^{1}$, Elaldi $\mathrm{R}^{1,2}$, Poissonnet $\mathrm{G}^{2}$, Sudaka $\mathrm{A}^{3}$, Bozec $\mathrm{A}^{2}$, Bekri $\mathrm{S}^{1, \mathrm{e}}$, Cazareth $\mathrm{J}^{1}$, Ponzio $\mathrm{G}^{1}$, Barbry $\mathrm{P}^{1}$, Rezzonico $\mathrm{R}^{1}$, Mari $\mathrm{B}^{1}$, Braud $\mathrm{VM}^{1}$ and Anjuère $\mathrm{F}^{1, \S}$.

${ }^{1}$ Université Côte d'Azur, CNRS UMR7275, Institut de Pharmacologie Moléculaire et Cellulaire, Valbonne, France

${ }^{2}$ Institut Universitaire de la Face et du Cou, Nice, France

${ }^{3}$ Centre Antoine Lacassagne, Pathology laboratory and Human biobank, Nice, France

\section{Present address:}

${ }^{\text {a } U n i v e r s i t y ~ C o ̂ t e ~ d ' A z u r, ~ I N S E R M, ~ U 1065, ~ C 3 M, ~ N i c e, ~ F r a n c e . ~}$

${ }^{\mathrm{b}}$ Inflammation Biology and Cancer Immunology, Peter Gorer Department of Immunobiology, King's College London, SE1 1UL London, UK.

${ }^{\text {c }}$ Department of Cell, Developmental \& Cancer Biology, Oregon Health \&Science University, 3181 SW Sam Jackson Park Road, Portland, OR, 97239, USA

${ }^{\mathrm{d}}$ CeMM Research Center for Molecular Medicine of the Austrian Academy of Sciences, 1090 Vienna, Austria.

e Tisch Cancer Institute, Mt Sinai School of Medicine, New York, NY 10029.

* equal contribution

§ corresponding author : Dr. Fabienne Anjuère, anjuere@ipmc.cnrs.fr 


\section{ABSTRACT}

Natural killer cells and tissue-resident ILC are innate effectors found in the skin. To investigate their temporal dynamics and specific functions throughout the development of cutaneous squamous cell carcinoma (cSCC), we combined transcriptomic and immunophenotyping analyses in mouse and human cSCC. We identified an infiltration of NK cells, and ILC1 as well as the presence of a few ILC3s. Adoptive transfer of NK cells in NK cell- and ILC-deficient $\mathrm{Nfil}^{-/-}$mice revealed a role for NK cells in early control of cSCC. During tumor progression, we identified a population skewing with the infiltration of atypical ILC1 secreting inflammatory cytokines but reduced levels of IFN- $\gamma$ at the papilloma stage. NK cells and ILC1 were functionally impaired, with reduced cytotoxicity and IFN- $\gamma$ secretion associated with the downregulation of activating receptors. They also showed a high degree of heterogeneity in mouse and human cSCC with the expression of several markers of exhaustion, including TIGIT on NK cells, and PD-1 and TIM-3 on ILC1. Our data show an enrichment in inflammatory ILC1 at precancerous stage together with impaired antitumor functions in NK cells and ILC1 that could contribute to the development of cSCC and thus suggest that future immunotherapies should take both ILC populations into account. 


\section{INTRODUCTION}

Cutaneous squamous cell carcinomas (cSCC) are the $2^{\text {nd }}$ most deadly skin cancer. They are treated by surgery but can reach a stage of advanced disease associated with rapid local relapse (Karia et al., 2013). Blockade of the PD-1 - PD-L1 inhibitory axis has provided promising results in patients with cSCC (Migden et al., 2020), leading to the approval of Cemiplimab for the treatment of patients with locally advanced or metastatic cSCC. The complete response rate is only $10 \%$, highlighting that further understanding of the immunosuppressive tumor microenvironment (TME) may help to better predict response and to propose novel immunotherapies.

In addition to $\mathrm{CD}^{+}$cytotoxic T effectors, the tumor infiltration by Natural Killer (NK) cells is associated with favorable outcomes in solid cancers (Gentles et al., 2015). Nevertheless, NK cells can display functional alterations as cancer progresses (Myers and Miller, 2020). Therapeutic approaches targeting NK cell inhibitory receptors and NK cell functions have shown promising results in hematopoietic and solid cancers (Devillier et al., 2020, Myers and Miller, 2020). Immunotherapeutic strategies targeting NK cell engagers like NKG2A or immune checkpoint inhibitors including PD-1, TIM-3, LAG-3 and TIGIT are under clinical investigation.

NK cells belong to a large family of Innate Lymphoid Cells (ILC) contributing to immunity and tissue homeostasis (Meininger et al., 2020). On the basis of cell surface markers, transcription factor requirement and cytokine secretion, ILC have been classified into NK cells, ILC1, ILC2, ILC3 and Lymphoid Tissue-Inducer cells (Vivier et al., 2018). Contrary to ILC that are mostly localized in epithelial tissues, NK cells can be recruited from the circulation and harbor potent perforin- and granzyme-dependent cytotoxicity after recognition of various stress signals from pathogenic cells. Group 1 ILC, which include NK cells and ILC1, share expression of the activating receptor NKp46 and secretion of IFN- $\gamma$ but they display phenotypic and 
functional heterogeneity (Riggan et al., 2019). Besides, NKp46 marker is used to define a subset of epithelial ILC3 (Luci et al., 2009, Sanos et al., 2009, Satoh-Takayama et al., 2008). This extended family of ILCs has brought questions about their contribution in shaping immune responses during pathological processes. The role of ILC subsets in cancer immune surveillance alongside NK cells still needs to be thoroughly evaluated (Chiossone et al., 2018).

In this context, we investigated the nature and role of $\mathrm{NKp} 46^{+}$cells in mouse and human cSCC, taking advantage of two mouse models of skin carcinogenesis and human cSCC biopsies. Our data reveal distinct in vivo dynamics and immune dysfunctions for NK cells and ILC1 infiltrating cSCC that can regulate tumor development.

\section{RESULTS}

\section{Early control of cutaneous squamous cell carcinoma by NK cells}

To assess the contribution of NKp46 ${ }^{+}$cells to cSCC progression, we used the well-established mouse model of chemically induced cutaneous carcinogenesis (Abel et al., 2009, Owens et al., 1999) (Supplementary Figure S1a). DMBA/PMA treatment promotes papillomas, which can develop into invasive cSCC (Supplementary Figure S1b and c). We also grafted mice intradermally with the mSCC38 murine cell line (Gastaldi et al., 2014) and monitored tumor development (Supplementary Figure S1d and (Khou et al., 2020). In these two cSCC models,

tumors are infiltrated with NKp46 ${ }^{+}$cells (Figure 1a and b). Reduced proportions and absolute numbers of $\mathrm{NKp} 46^{+}$cells were observed at papilloma stage compared to the other conditions (Figure 1a and b).

To investigate their role, we monitored cSCC outgrowth in $N f i l 3^{-/-}$mice. These mice display immune dysfunctions including a lack of NK cells and other ILC subsets (Daussy et al., 2014, Geiger et al., 2014), although tissue-resident NK cells have been found in Nfil3-/- C57BL/6 mice (Sojka et al., 2014). On FVB/N background, $\mathrm{NKp} 46^{+}$cells were found absent in skin, 
papillomas, tumors and lymph nodes of DMBA/PMA-treated $N f i 3^{-/-}$FVB/N mice (Supplementary Figure S1e), When compared to WT littermates, $\mathrm{Nfil}^{-/-}$mice developed significantly more papillomas (Figure 1c), indicating that the immune dysfunction of $\mathrm{Nfil}^{-/-}$ mice increased their susceptibility to skin carcinogenesis. The growth of mSCC38 tumors was also increased in $\mathrm{Nfil}^{-/-}$mice compared with that in wild-type littermates (Figure 1d). Tumor growth was significantly increased at early time points in both models (Figure 1c and d, grey boxes). We then addressed the direct contribution of NK cells by transferring cell-sorted NK cells in mSCC38 tumor-bearing $\mathrm{Nfil3}^{-/-}$mice (Supplementary Figure S1f), which reduced tumor burden to a level comparable to-with that in wild-type littermates (Figure 1d). Thus, NKp46 ${ }^{+}$ NK cells contribute to the early control of cSCC.

\section{Distinct temporal infiltration of NK cells and ILC1 during cSCC}

To deeply characterize the nature of infiltrated $\mathrm{NKp}^{+} 6^{+}$cells over the course of cSCC progression, we performed a transcriptomic analysis of cell-sorted $\mathrm{NKp}^{+} 6^{+}$cells from papillomas, tumors, perilesional skins of DMBA and PMA-treated mice and from skin of control PMA-treated mice. Exploratory Principal Component Analysis (PCA) was generated on the $10 \%$ most variable probesets. PC1 axis explaining the largest percentage of variability (65.4\%) separated papillomas from skins and tumors. PC2 axis (17.9\%) highlighted the singularity of tumor-associated $\mathrm{NKp}^{+} 6^{+}$cells (Figure 2a). Hierarchical clustering underlined the unique gene expression profiles of papilloma and tumor samples (Figure 2b). The highest numbers of differentially expressed genes (DEGs) were found in the contrasts including papilloma-associated $\mathrm{NKp}^{+} 6^{+}$cells, stressing that at this stage the cells harbored the most divergent gene signature (Figure 2c).

Because NKp46 is expressed by NK cells, ILC1 and ILC3, we examined the heterogeneity of $\mathrm{NKp}_{4} 6^{+}$cells. Taking advantage of published gene signatures (Robinette et al., 2015), we 
selected two restricted cores of genes that were able to discriminate NK cells from other ILC (Figure 3a and Supplementary Table S1). The comparison of these gene signatures with our transcriptomic data showed that papilloma-associated $\mathrm{NKp}^{+} 6^{+}$cells were enriched in genes from the ILC core, such as Il7r or Cxcr6 and were poor in genes from the NK core such as Eomes, Zeb2 or Irf8. We then used the CIBERSORT computational method (Newman et al., 2015) and a NK and ILC public dataset (Robinette et al., 2015) to build specific gene signatures that discriminate NK cells, ILC1 and ILC3 (Supplementary Table S2). We confronted these signatures with our dataset to quantify the proportion of each $\mathrm{NKp} 46^{+}$subset. This highlighted an enrichment in ILC1 within papilloma-associated $\mathrm{NKp} 46^{+}$cells compared with those in the other samples which were enriched in NK cells (Figure 3b). We also detected a small proportion of ILC3 (3.5\% and 4.8\% of the NKp46 ${ }^{+}$cells in papillomas and PMA skin, respectively).

The transcription factor EOMES is critical for NK cell development and the IL-7 receptor $\alpha$ chain (CD127) is mostly associated with ILC1 and ILC3 phenotypes (Daussy et al., 2014, Gordon et al., 2012, Robinette et al., 2015, Serafini et al., 2015). We confirmed by flow cytometry that the proportion of EOMES ${ }^{+} \mathrm{NKp}_{4} 6^{+}$cells in papillomas was lower than in the tumors and skin samples (Figure 3c and d). Conversely, the fraction of CD127 ${ }^{+} \mathrm{NK} 46^{+}$cells was higher in papillomas than in other samples (Figure 3d).

These data highlight the heterogeneity of $\mathrm{NKp}_{4} 6^{+}$cells during skin carcinogenesis and show that papilloma-associated NKp46 ${ }^{+}$cells are enriched in ILC1, whereas NK cells are prominent in tumors and skin surrounding lesions.

\section{Functional dysregulations of NK cells and ILC1 characterize papilloma and tumor stages}

We next assessed the functional properties of papilloma and tumor-associated $\mathrm{NKp} 46^{+}$cells. We found that a lower proportion of $\mathrm{NKp} 6^{+}$cells expressed IFN- $\gamma$ at papilloma and tumor 
stages in response to in vitro stimulation with IL-12 and IL-18 cytokines (Figure 4a). The reduced expression of IFN- $\gamma$ by NKp46 ${ }^{+}$cells was also detected on stimulation with PMA and ionomycin at the papilloma stage and was associated with a reduced degranulation (Figure 4b, left and right panels). Thus, $\mathrm{NKp} 6^{+}$cells are dysfunctional at papilloma and tumor stages compared with their skin counterparts.

To further understand functional differences between papilloma- and tumor-associated NKp46 ${ }^{+}$ cells, we analyzed the genes associated with cytotoxicity. The hierarchical clustering of these genes underlined the unique functional features of $\mathrm{NKp} 46^{+}$cells at papilloma and tumor stages (Figure 4c). Tnfsf10 encoding TRAIL was significantly enriched at the papilloma stage contrary to granzyme B (Gzmb) and perforin (Prf) (Figure 4c and Supplementary Figure 2a). In addition, several granzymes including granzyme D, E, F and G genes that is, Gzmd, Gzme, Gzmf, Gzmg genes, respectively, were only expressed at the tumor stage (Figure 4c and Supplementary Table S3). These results are consistent with the distinct temporal infiltration of NK cells and ILC1 seen in the CIBERSORT analysis. We confirmed this result at the protein level using flow cytometry by showing that TRAIL-expressing ILC1 were increased in papillomas, as described for tissue-resident ILC1 (Figure 4d and (Daussy et al., 2014, Luci et al., 2015). These ILC1 did not express much of granzymes A and B, whereas a majority of NK cells expressed granzyme B but displayed reduced levels of granzyme A (Figure 4d). Thus, the reduced cytotoxicity in $\mathrm{NKp}_{4} 6^{+}$cells at the papilloma stage is consistent with an increased proportion of poorly cytolytic ILC1.

We then analyzed the cytokines that exhibited detectable levels of transcripts at least in one tissue sample (Figure 4e and Supplementary Table S3). The hierarchical clustering revealed the cytokines mostly expressed at the papilloma stage, namely Csf2 encoding GM-CSF, Cxcl1 and Cxcl2 encoding mouse homologues of IL-8, Tnf and several interleukins (Il1b, IL17a, Il17f, Il4, IL13, Il6). At the tumor stage, Il2 and Ifng genes were decreased compared with those in the 
other conditions. At the protein level, as detected by flow cytometry, NK cells and ILC1 secreted IFN- $\gamma$ upon PMA and ionomycin stimulation but a lower proportion of ILC1 secreted IFN- $\gamma$ at the papilloma stage (Figure $4 \mathrm{f}$ ). TNF- $\alpha$ was produced predominantly by ILC1 in all the samples (Figure 4f). Interestingly, we detected a significant increased expression of IL-6 by ILC1 at the papilloma stage, indicating that they display an inflammatory phenotype.

These data show that ILC1 are enriched at the papilloma stage, are poorly cytolytic and switch from an IFN- $\gamma$ to an IL-6 inflammatory profile. Tumor-associated NK cells have impaired cytolytic function and IFN- $\gamma$ production that can be partially restored on in vitro stimulation.

\section{NK cells and ILC1 infiltrating mouse cSCC display markers of exhaustion}

To investigate the mechanisms associated with impaired functions of NK cells and ILC1, we analyzed the genes associated with NK and/or ILC activation. Consistent with impaired functions, we detected that several genes encoding activating receptors were downregulated in $\mathrm{NKp}_{4}{ }^{+}$cells from papillomas and/or tumors, including Klrc2 (NKG2C), Cd226 (DNAM-1), CD28, Klrb1c (NKR-P1C) and Klrk1 (NKG2D) whereas the co-inhibitory receptors associated

with exhaustion such as CD96, Pdcd1 (PD-1), Havcr2 (Tim-3), Ctla4, Tigit and Lag3 were upregulated at the tumor stage (Figure 5a, Supplementary Figure 2c and b and Supplementary Table S3).

To identify a potential heterogeneity at the protein level, we first evaluated the differential expression of CD49b, CD49a, PD-1, TIM-3, LAG-3 and CTLA-4 markers in live CD3-NKp46 ${ }^{+}$ cells from mSCC38 tumors by flow cytometry using t-distributed stochastic neighbor embedding (tSNE) analysis (Figure 5b). NK cells and ILC1 were discriminated by the expression of CD49b and CD49a respectively, and the expression of either one or two exhaustion markers pinpointed their heterogeneity (Figure 5b). In addition, two additional flow cytometry stainings showed that most exhaustion markers (CD96, PD-1, TIM-3, and LAG-3) 
and activating receptors (NKG2D and DNAM-1) were expressed by a significantly higher proportion of ILC1 than NK cells (Figure 5c and d). The combination of markers also identified TIM-3 ${ }^{+} \mathrm{PD}-1^{+}$ILC1 and CD96 ${ }^{+} \mathrm{CD} 28^{+}$ILC1 (Figure 5b and c). Conversely, 50\% of NK cells expressed NKG2D but they did not express DNAM-1 known to promote the killing of cells expressing the CD112 and CD155 ligands (Stanietsky et al., 2009), consistent with their TGF$\beta$ imprinting (Cortez et al., 2017). Tumor-associated NK cells expressed the highest proportion of the coinhibitory molecule TIGIT as well as the coinhibitory receptor CD96 also interacting with CD112 and/or CD155 (Figure 5d).

Our data identified heterogeneous subsets of mouse NK cells and ILC1 displaying different combinations of exhaustion markers and NK cells exhibiting an unbalanced expression of DNAM-1, TIGIT and CD96 receptors that may explain their dysfunctions in the TME.

\section{Human cSCC are infiltrated with heterogeneous subsets of NK cells and NKp46 ${ }^{+}$ILC}

To extend our findings to human cSCC, we assessed the proportions of NK cells and ILC subsets in fresh biopsies by flow cytometry (Supplementary Table S4). Using CD56, CD127, CD117 and CD294 markers to differentiate between NK cells, ILC1, ILC2 and ILC3 (Vely et al., 2016), we found that human cSCC were mainly infiltrated with NK cells, ILC1 and a small subset of ILC3 but no ILC2 (Figure 6a and Supplementary Figure S3a). Using an antibody panel targeting NKp46, CD56 and CD127 markers together with the lineage markers CD3, CD14, CD15 and CD19, we identified NKp46 ${ }^{+}$NK cells expressing variable levels of CD56 as the most prominent cell population and subsets of $\mathrm{NKp} 46^{+-} \mathrm{CD} 127^{+}$ILC consistent with ILC1 and ILC3 phenotypes (Figure 6b and Supplementary Figure S3b). These results are in agreement with the NKp46 ${ }^{+}$subsets identified in mouse cSCC (Figure 3b, c and d).

We next evaluated the co-expression of a selected set of NK and/or ILC cell surface receptors (CD56, NKp46, CD127) with co-inhibitory receptors (CD161, TIGIT, TIM-3, PD-1) on live 
$\mathrm{CD}^{-C D} 19^{-C D} 15^{-C D} 14^{-}$cells from healthy distant skin, perilesional skin and cSCC biopsies by flow cytometry and computational analysis (Figure 6c). The t-SNE analysis revealed that the $\mathrm{NKp}_{4} 6^{+}$and $\mathrm{CD} 56^{+} \mathrm{NK}$ cell populations were the most abundant in tumors while CD127 ILC were the most prominent in distant and perilesional skins, consistent with their tissue residency (Figure 6c and d).

To identify the specific phenotypes of NK cells and ILC infiltrating the tumors, we separated NK cells and ILC subsets into 40 meta-clusters (MC) using the FlowSOM clustering tool. The complete linkage hierarchical clustering of samples and mean-centered MC cell proportions revealed four MC groups significantly enriched in tumor samples and corresponding to NK cell subsets (Figure 6e, red, purple, blue and green arrows). The first MC group identified $\mathrm{CD}^{+} 6^{+} \mathrm{NKp} 46^{+}$cells as the most enriched subset in tumor samples (Figure 6f, red cells from MC8, MC9 and MC17). These cells did not express CD127 (Figure 6c). The second MC group gathered $\mathrm{CD} 56^{+} \mathrm{NKp} 46^{\text {low/- }}$ cells that may correspond to NK cells that have downregulated the NKp46 activating receptor (Figure 6f, purple cells from MC5, MC10 and MC11). Some of these cells expressed low levels of TIGIT, TIM-3 or PD-1 markers. The third MC group identified CD56 ${ }^{\text {low }} \mathrm{NKp} 46^{+} \mathrm{TIGIT}^{+}$cells significantly enriched in tumors compared with those in distant skin (Figure 6f, blue cells from MC14, MC15, MC20 and MC21), consistent with the functionally compromised NK cells identified in mouse cSCC (Figure 5e). The fourth MC group corresponding to $\mathrm{CD}^{+} 6^{+} \mathrm{NKp} 46^{-} \mathrm{TIGIT}^{+} \mathrm{PD}-1^{+} \mathrm{TIM}-3^{+}$cells was restricted to tumor samples and accounted for around 3\% of total NK and/or ILC (Figure 6f, green cells from MC25).

Thus, human cSCC are infiltrated with NK cells, ILC1 and few ILC3. NK cells are the most abundant innate lymphoid cells of human cSCCs and express several specific exhaustion markers, particularly TIGIT, suggesting a TIGIT-induced inhibitory axis. 


\section{DISCUSSION}

NK cells and skin-resident ILC subsets are innate effectors found in the skin. In this study, we analyze the composition of NKp46 $6^{+}$type-1 ILC infiltrating mouse and human cSCCs, which reveals heterogeneous subsets of NK cells, ILC1s and very few ILC3s over the course of cSCC. ILC1 are prominent at the papilloma stage and harbor an atypical cytokine secretion pattern with reduced IFN- $\gamma$ production and secretion of IL-2, IL-6 and TNF- $\alpha$. NK cells and ILC1s from lesions are dysfunctional with reduced cytotoxicity and IFN- $\gamma$ secretion, associated with the downregulation of activating receptors and the expression of co-inhibitory molecules. Thus, our study shows that the enrichment of inflammatory ILC1 at precancerous stage together with impaired antitumor functions of NK cells and ILC1 could contribute to cSCC development.

NK cells are innate effectors eliminating cancer cells and their infiltration in solid tumors has been associated with favorable clinical outcomes (Gentles et al., 2015). They act as the first line of defense and can enhance adaptive immune responses (Bihl et al., 2010, Smyth et al., 2001). In two mouse models of cSCCs, the antitumor activity observed at early time points was attributed to NK cells. The detection of significant proportions of ILC1 and a few ILC3 raise the question about their role in cancer. Indeed, they share with NK cells, phenotypes and functions that vary across tissues and states of activation, making them difficult to differentiate (Riggan et al., 2019). Our study reveals distinct in vivo dynamics for NK cells and ILC1 throughout cSCC development. We postulate that the enrichment of ILC1 at the papilloma stage which participates in the impaired cytotoxicity and IFN- $\gamma$ secretion of $\mathrm{NKp}^{+} 6^{+}$cells, is one mechanism that favors the conversion of papillomas into tumors. This may be linked with differential recruitment of NK and ILC1 or local redistribution of tissue-resident ILC1. Recent studies showed that on TGF- $\beta$ exposure, NK cells convert into ILC1-like cells (Cortez et al., 2017, Cuff et al., 2019). In cSCC, TGF- $\beta$ was identified as a main upstream regulator using Ingenuity Pathway Analysis of the NKp46 ${ }^{+}$transcriptomic dataset (not shown). The enrichment 
in ILC1 over NK cells at the papilloma stage may therefore be explained by the local repression of EOMES by TGF- $\beta$.

Specialized functional features characterize NK cells and ILC1. ILC1s express TRAIL and are poorly cytotoxic at the papilloma stage, consistent with the properties of tissue-resident ILC1 (Serafini et al., 2015) and thus differ from cytotoxic type-1-like ILC recently reported in a breast cancer model (Dadi et al., 2016). Papilloma-associated ILC1 have also an atypical proinflammatory cytokine phenotype with the secretion of IL-2, IL-6, IL-17 and TNF- $\alpha$, cytokines previously reported as protumor factors of the TME. IL-6 signaling decreases MHCII expression and IL-12 production by dendritic cells, thus reducing IFN- $\gamma$ production by CD4 ${ }^{+} \mathrm{T}$ cells (Narita et al., 2013, Ohno et al., 2016). IL-17 was shown to induce Stat3 activation and neutrophil infiltration, associated with bad prognosis in DMBA/PMA skin carcinogenesis (Khou et al., 2020). IL-17-secreting cells resemble ILC3 previously shown to promote inflammation at mucosal surfaces (Chan et al., 2014, Kirchberger et al., 2013). TNF- $\alpha$ has known angiogenic and protumor properties (Balkwill, 2009). Papilloma-associated ILC1s have the highest ratio of TNF- $\alpha^{+}$to IFN- $\gamma^{+}$cells, suggesting that these ILC1s contribute to tumor progression, similarly to ILC1s reported in a chemo-induced fibrosarcoma model (Gao et al., 2017). NK cells also show impaired functions at the tumor stage but, in vitro stimulation with PMA and ionomycin restores IFN- $\gamma$ production and significant cytotoxicity in NK cells whereas IL12- and IL18-driven production of IFN- $\gamma$ remains altered. This can be explained by a defect in the IL-18 receptor pathway in NK cells in the TME, as previously described in the hypoxic TME of mouse lymphoma model (Ni et al., 2020). This indicates that the TME acts on different receptors to promote NK and ILC1 immune dysfunctions.

Such role of the TME can be exemplified by the downregulation of activating receptors and the expression of coinhibitory receptors in mouse and human cSCCs. Markers of exhaustion have been reported on NK cells and ILC subsets and immunotherapy has therefore enhanced 
antitumor activity of NK/ILC cells (Crinier et al., 2019, Devillier et al., 2020, Myers and Miller, 2020, Sivori et al., 2019). Exhaustion markers include PD-1, TIM-3, LAG-3 and TIGIT (Cortez et al., 2017, Gao et al., 2017). More specifically, PD-1/PD-L1 and TIGIT blockade led to sustained tumor-specific T cell immunity in an NK cell-dependent manner (Hsu et al., 2018, Zhang et al., 2018). TIGIT is a dominant marker of tumor-associated NK cells in mouse and human cSCCs, suggesting it plays a role in NK cell dysfunction. Besides, the consequences of the expression of immune checkpoint markers mainly PD-1 and TIM-3 on NK cells and ILC1 remain to be clarified. Further works based on in situ integrative analyses, including multiplexed imaging and spatial transcriptomics of human SCC in line with recent data (Ji et al., 2020) and including markers to discriminate subsets of NK cells and other ILCs will be therefore important to unravel the specific contribution of ILC1s and NK cells subsets within the cSCC TME.

Altogether, our results show functional alterations combined with phenotypic modulations leading to the infiltration of cSCCs by heterogeneous subsets of ILC1 and NK cells in a temporal manner which might participate to cSCC progression. This study is valuable for future immunotherapies targeting cSCCs and particularly for patients at high risk of relapse.

\section{MATERIALS AND METHODS}

\section{Mice and mouse tumor models}

The DMBA and PMA model of chemically-induced cutaneous carcinogenesis and the mSCC38 tumor model, described in Supplementary Material and Methods, were developed in FVB/N mice (Charles River Laboratories, St Germain Nuelles, France), $N f i l 3^{-/-}$deficient and littermate control mice on FVB/N background.

\section{Patient biopsies}

cSCC biopsies and control skins were obtained at the Centre Antoine Lacassagne (CAL, Nice, 
France).

\section{Cell preparations}

Cell suspensions from mouse skins, mouse papilloma and tumor tissues, and human samples were prepared enzymatically as described in Supplementary Materials and Methods.

\section{Flow cytometry and computational analysis}

Flow cytometry stainings were performed with the antibodies listed in Supplementary Tables S5 and S6 on mouse and human cells, respectively. NK cells and ILC were analyzed using computational tools as described in Supplementary Materials and Methods.

\section{Functional assays}

Cytokine production and degranulation were measured after in vitro stimulation on mouse cell suspensions as described in Supplementary Materials and Methods.

\section{RNA extraction and microarrays}

RNA was extracted from sorted $\mathrm{NKp}_{4} 6^{+}$cells and cRNA were hybridized to SurePrint G3 Mouse GE 8x60K microarrays (Agilent Technologies, Massy, France). The microarray data were normalized and differential analysis performed as provided in Supplementary Materials and Methods.

\section{Transcriptomic data analysis}

The transcriptomes were compared using PCA and exploratory hierarchical clustering tools. The cell populations in $\mathrm{NKp}^{+} 6^{+}$samples were quantified using the CIBERSORT method 
(Newman et al., 2015) and specific signatures for ILC1, ILC3 and NK cells (Robinette et al., 2015) as described in Supplementary Materials and Methods.

\section{Statistics}

Statistical analyses were carried out with Prism software version 6.0 (GraphPad Prism, San Diego, California, USA).

\section{Data Availability statement}

The data have been deposited in the Gene Expression Omnibus database (https://www.ncbi.nlm.nih.gov/geo) [accession nos. GSE84027]).

\section{ORCIDs}

Carmelo Luci : http://orcid.org/0000-0001-9687-4164

Franck Bihl : https://orcid.org/0000-0002-8808-8152

Pierre Bourdely : https://orcid.org/0000-0002-4162-1490

Sokchea Khou : https://orcid.org/0000-0002-5386-9856

Alexandra Popa : https://orcid.org/0000-0001-7156-272X

Aida Meghraoui-Kheddar : https://orcid.org/0000-0002-7440-5495

Ophelie Vermeulen : https://orcid.org/0000-0003-4611-2916

Roxane Elaldi : https://orcid.org/0000-0002-0381-6481

Gilles Poissonnet : https://orcid.org/0000-0002-9022-4352

Anne Sudaka : https://orcid.org/ 0000-0001-5729-0465

Alexandre Bozec : https://orcid.org/0000-0002-8576-3052

Selma Bekri : https://orcid.org/0000-0003-2045-386X

Julie Cazareth : https://orcid.org/0000-0002-8482-209X 
Giles Ponzio : https://orcid.org/0000-0003-2741-0248

Pascal Barbry : https://orcid.org/0000-0001-9632-6483

Roger Rezzonico : https://orcid.org/0000-0002-8460-1641

Bernard Mari : https://orcid.org/0000-0002-0422-9182

Veronique M. Braud: https://orcid.org/0000-0001-8213-3947

Fabienne Anjuère : https://orcid.org/0000-0003-3144-8652

\section{CONFLICT OF INTEREST}

The authors state no conflict of interest.

\section{ACKNOWLEDGMENTS}

We would like to thank Vanina Simon, Kelly Nouhen, Hadi Zarif, Sébastien Grosso, Alain Rubod, Morgane Roulot and Belinda Desrues for hepful technical assistance. We thank Dr Isabelle Peyrottes, Dr Juliette Haudebourg and Dr. Julien Boyer as well as all the technical staff of the pathology laboratory of the Centre Antoine Lacassagne (CAL, nice, France) for the extemporaneous preparation of human biopsies and histological analyses. This study was supported by the following funding agencies: French Government (National Research Agency, ANR) through the "Investments for the Future" programs LABEX SIGNALIFE ANR-11LABX-0028 and IDEX UCAJedi ANR-15-IDEX-01; Cancéropole PACA; Centre National de la Recherche Scientifique; Institut national de la santé et de la recherche médicale; Université Côte d'Azur; Région Provence-Alpes-Côte d'Azur; Fondation ARC pour la recherche sur le Cancer; Fondation de l'Avenir ; Ligue Nationale contre le Cancer; Fondation d'entreprise SILAB Jean PAUFIQUE. We thank the IPMC’s UCAGenomiX, Imaging/Flow cytometry and animal house core facilities for providing assistance. 


\section{AUTHOR CONTRIBUTIONS}

Conceptualization: CL, FB, VMB, FA; Formal Analysis: CL, FB, PiB, SK, AP, AMK, OV, SB, FA; Funding Acquisition: CL, VMB, FA; Project Administration: VMB, FA; Ressources: RE, GP, AS, AB, JC, GiP, PaB, RR, BM; Supervision: FA; Writing-Original Draft Preparation: CL, VMB, FA. 


\section{REFERENCES}

Abel EL, Angel JM, Kiguchi K, DiGiovanni J. Multi-stage chemical carcinogenesis in mouse skin: fundamentals and applications. Nature protocols 2009;4:1350-62.

Balkwill F. Tumour necrosis factor and cancer. Nat Rev Cancer 2009;9:361-71.

Bihl F, Pecheur J, Breart B, Poupon G, Cazareth J, Julia V, et al. Primed antigen-specific CD4+ T cells are required for NK cell activation in vivo upon Leishmania major infection. J Immunol 2010;185:2174-81.

Chan IH, Jain R, Tessmer MS, Gorman D, Mangadu R, Sathe M, et al. Interleukin-23 is sufficient to induce rapid de novo gut tumorigenesis, independent of carcinogens, through activation of innate lymphoid cells. Mucosal immunology 2014;7:842-56.

Chiossone L, Dumas PY, Vienne M, Vivier E. Natural killer cells and other innate lymphoid cells in cancer. Nat Rev Immunol 2018;18:671-88.

Cortez VS, Ulland TK, Cervantes-Barragan L, Bando JK, Robinette ML, Wang Q, et al. SMAD4 impedes the conversion of NK cells into ILC1-like cells by curtailing non-canonical TGF-beta signaling. Nat Immunol 2017;18:995-1003.

Crinier A, Vivier E, Blery M. Helper-like innate lymphoid cells and cancer immunotherapy. Semin Immunol 2019;41:101274.

Cuff AO, Sillito F, Dertschnig S, Hall A, Luong TV, Chakraverty R, et al. The Obese Liver Environment Mediates Conversion of NK Cells to a Less Cytotoxic ILC1-Like Phenotype. Front Immunol 2019;10:2180.

Dadi S, Chhangawala S, Whitlock BM, Franklin RA, Luo CT, Oh SA, et al. Cancer Immunosurveillance by Tissue-Resident Innate Lymphoid Cells and Innate-like T Cells. Cell 2016;164:365-77.

Daussy C, Faure F, Mayol K, Viel S, Gasteiger G, Charrier E, et al. T-bet and Eomes instruct the development of two distinct natural killer cell lineages in the liver and in the bone marrow. The Journal of experimental medicine 2014;211:563-77.

Devillier R, Chretien AS, Pagliardini T, Salem N, Blaise D, Olive D. Mechanisms of NK cell dysfunction in the tumor microenvironment and current clinical approaches to harness NK cell potential for immunotherapy. J Leukoc Biol 2020.

Gao Y, Souza-Fonseca-Guimaraes F, Bald T, Ng SS, Young A, Ngiow SF, et al. Tumor immunoevasion by the conversion of effector NK cells into type 1 innate lymphoid cells. Nat Immunol 2017;18:1004-15.

Gastaldi C, Bertero T, Xu N, Bourget-Ponzio I, Lebrigand K, Fourre S, et al. miR-193b/365a cluster controls progression of epidermal squamous cell carcinoma. Carcinogenesis 2014;35:1110-20.

Geiger TL, Abt MC, Gasteiger G, Firth MA, O'Connor MH, Geary CD, et al. Nfil3 is crucial for development of innate lymphoid cells and host protection against intestinal pathogens. The Journal of experimental medicine 2014;211:1723-31.

Gentles AJ, Newman AM, Liu CL, Bratman SV, Feng W, Kim D, et al. The prognostic landscape of genes and infiltrating immune cells across human cancers. Nat Med 2015;21:938-45.

Gordon SM, Chaix J, Rupp L, Wu J, Madera S, Sun JC, et al. The transcription factors T-bet and Eomes control key checkpoints of natural killer cell maturation. Immunity 2012;36:55-67.

Hsu J, Hodgins JJ, Marathe M, Nicolai CJ, Bourgeois-Daigneault MC, Trevino TN, et al. Contribution of NK cells to immunotherapy mediated by PD-1/PD-L1 blockade. J Clin Invest 2018;128:4654-68.

Ji AL, Rubin AJ, Thrane K, Jiang S, Reynolds DL, Meyers RM, et al. Multimodal Analysis of Composition and Spatial Architecture in Human Squamous Cell Carcinoma. Cell 2020;182:1661-2.

Karia PS, Han J, Schmults CD. Cutaneous squamous cell carcinoma: estimated incidence of disease, nodal metastasis, and deaths from disease in the United States, 2012. J Am Acad Dermatol 2013;68:957-66.

Khou S, Popa A, Luci C, Bihl F, Meghraoui-Kheddar A, Bourdely P, et al. Tumor-Associated Neutrophils Dampen Adaptive Immunity and Promote Cutaneous Squamous Cell Carcinoma Development. Cancers (Basel) 2020;12. 
Kirchberger S, Royston DJ, Boulard O, Thornton E, Franchini F, Szabady RL, et al. Innate lymphoid cells sustain colon cancer through production of interleukin-22 in a mouse model. The Journal of experimental medicine 2013;210:917-31.

Luci C, Bekri S, Bihl F, Pini J, Bourdely P, Nouhen K, et al. NKp46+ Innate Lymphoid Cells Dampen Vaginal CD8 T Cell Responses following Local Immunization with a Cholera Toxin-Based Vaccine. PloS one 2015;10:e0143224.

Luci C, Reynders A, Ivanov, II, Cognet C, Chiche L, Chasson L, et al. Influence of the transcription factor RORgammat on the development of NKp46+ cell populations in gut and skin. Nature immunology 2009;10:75-82.

Meininger I, Carrasco A, Rao A, Soini T, Kokkinou E, Mjosberg J. Tissue-Specific Features of Innate Lymphoid Cells. Trends Immunol 2020;41:902-17.

Migden MR, Khushalani NI, Chang ALS, Lewis KD, Schmults CD, Hernandez-Aya L, et al. Cemiplimab in locally advanced cutaneous squamous cell carcinoma: results from an open-label, phase 2 , single-arm trial. Lancet Oncol 2020;21:294-305.

Myers JA, Miller JS. Exploring the NK cell platform for cancer immunotherapy. Nat Rev Clin Oncol 2020.

Narita Y, Kitamura H, Wakita D, Sumida K, Masuko K, Terada S, et al. The key role of IL-6-arginase cascade for inducing dendritic cell-dependent $\mathrm{CD} 4(+) \mathrm{T}$ cell dysfunction in tumor-bearing mice. J Immunol 2013;190:812-20.

Newman AM, Liu CL, Green MR, Gentles AJ, Feng W, Xu Y, et al. Robust enumeration of cell subsets from tissue expression profiles. Nature methods 2015;12:453-7.

Ni J, Wang X, Stojanovic A, Zhang Q, Wincher M, Buhler L, et al. Single-Cell RNA Sequencing of TumorInfiltrating NK Cells Reveals that Inhibition of Transcription Factor HIF-1alpha Unleashes NK Cell Activity. Immunity 2020;52:1075-87 e8.

Ohno Y, Kitamura H, Takahashi N, Ohtake J, Kaneumi S, Sumida K, et al. IL-6 down-regulates HLA class II expression and IL-12 production of human dendritic cells to impair activation of antigenspecific CD4(+) T cells. Cancer Immunol Immunother 2016;65:193-204.

Owens DM, Wei S, Smart RC. A multihit, multistage model of chemical carcinogenesis. Carcinogenesis 1999;20:1837-44.

Riggan L, Freud AG, O'Sullivan TE. True Detective: Unraveling Group 1 Innate Lymphocyte Heterogeneity. Trends Immunol 2019;40:909-21.

Robinette ML, Fuchs A, Cortez VS, Lee JS, Wang Y, Durum SK, et al. Transcriptional programs define molecular characteristics of innate lymphoid cell classes and subsets. Nature immunology 2015;16:306-17.

Sanos SL, Bui VL, Mortha A, Oberle K, Heners C, Johner C, et al. RORgammat and commensal microflora are required for the differentiation of mucosal interleukin 22-producing NKp46+ cells. Nature immunology 2009;10:83-91.

Satoh-Takayama N, Vosshenrich CA, Lesjean-Pottier S, Sawa S, Lochner M, Rattis F, et al. Microbial flora drives interleukin 22 production in intestinal NKp46+ cells that provide innate mucosal immune defense. Immunity 2008;29:958-70.

Serafini N, Vosshenrich CA, Di Santo JP. Transcriptional regulation of innate lymphoid cell fate. Nature reviews Immunology 2015;15:415-28.

Sivori S, Vacca P, Del Zotto G, Munari E, Mingari MC, Moretta L. Human NK cells: surface receptors, inhibitory checkpoints, and translational applications. Cell Mol Immunol 2019;16:430-41.

Smyth MJ, Crowe NY, Godfrey DI. NK cells and NKT cells collaborate in host protection from methylcholanthrene-induced fibrosarcoma. Int Immunol 2001;13:459-63.

Sojka DK, Plougastel-Douglas B, Yang L, Pak-Wittel MA, Artyomov MN, Ivanova Y, et al. Tissue-resident natural killer (NK) cells are cell lineages distinct from thymic and conventional splenic NK cells. eLife 2014;3:e01659.

Stanietsky N, Simic H, Arapovic J, Toporik A, Levy O, Novik A, et al. The interaction of TIGIT with PVR and PVRL2 inhibits human NK cell cytotoxicity. Proc Natl Acad Sci U S A 2009;106:17858-63.

Vely F, Barlogis V, Vallentin B, Neven B, Piperoglou C, Ebbo M, et al. Evidence of innate lymphoid cell redundancy in humans. Nat Immunol 2016;17:1291-9. 
Vivier E, Artis D, Colonna M, Diefenbach A, Di Santo JP, Eberl G, et al. Innate Lymphoid Cells: 10 Years On. Cell 2018;174:1054-66.

Zhang $\mathrm{Q}, \mathrm{Bi}$ J, Zheng $\mathrm{X}$, Chen $\mathrm{Y}$, Wang $\mathrm{H}, \mathrm{Wu} \mathrm{W}$, et al. Blockade of the checkpoint receptor TIGIT prevents NK cell exhaustion and elicits potent anti-tumor immunity. Nat Immunol 2018;19:723-32. 


\section{FIGURE LEGENDS}

\section{Figure 1. Reconstitution of $\mathrm{Nfil}^{-/-}$mice with NK cells restores cSCC immune}

\section{surveillance.}

(a-b) Frequencies and absolute numbers of $\mathrm{CD}^{-} \mathrm{NKp}^{+} 6^{+}$cells (a) in DMBA and PMA-treated mice, ( $\mathrm{n}=7-11$, mean values \pm SEM from three independent experiments; ${ }^{*} \mathrm{p}<0.05$, ${ }^{* *} \mathrm{p}<0.01$, ${ }^{* * *} \mathrm{p}<0,001$, Mann-Whitney $\mathrm{U}$ test) and (b) in mSCC38-bearing mice, ( $\mathrm{n}=3-4$ mice per group, mean values $\pm S D$, no statistical difference). Skin-surrounding papilloma indicates papilloma skin, skin-surrounding tumor indicates tumor skin, papilloma indicates DMBA and PMAinduced precancerous lesions and tumor indicates DMBA and PMA-induced carcinoma. (c) Kinetics of development of papillomas in $\mathrm{Nfil}^{-/-}$mice $(\mathrm{n}=19)$ and $\mathrm{Nfil3^{+/+ }}$ littermate controls ( $n=16$ ), (mean numbers of papillomas \pm SEM of two independent experiments, ${ }^{*} \mathrm{p}<0.05$, HolmSidak test). (d) schematic representation of mSCC38 tumor model and mSCC-38 tumor growth in $\mathrm{Nfil}^{+/+}$littermates $(\mathrm{n}=23)$ and in $N f i 3^{-/-}$mice transferred $(\mathrm{n}=8)$ or not transferred $(\mathrm{n}=16)$ with cell-sorted spleen NK cells on day 3 after the mSCC38 intradermal grafting, (mean \pm SEM of three independent experiments; ${ }^{*} \mathrm{p}<0.05$, Mann-Whitney $U$ test). (c-d) Gray boxes show the time points with statistical differences.

Figure 2. Gene expression profiles of $\mathrm{NKp}^{4}{ }^{+}$cells reveal stage-specific signatures.

(a-c)Transcriptomic analyses were performed on cell-sorted CD3-NKp46 ${ }^{+}$cells purified from the pools of skin of PMA-treated-mice ( $\mathrm{n}=19$ mice, two experiments) and the pools of the skin surrounding papillomas ( $\mathrm{n}=15$ mice, three experiments), the skin surrounding tumors ( $\mathrm{n}=17$ mice, three experiments), papillomas (118 papillomas from $n=5$ mice, two experiments) and tumors (23 tumors from $n=13$ mice, three experiments) from DMBA and PMA-treated mice. (a) Two-dimensional PCA, (b) hierarchical clustering of the $10 \%$ most variable probesets with a minimum log2 average expression of 6 and (c) DEG in pairwise comparisons (minimum log2 
average expression of 6 , an absolute log fold change of at least 1 , and an adjusted $P$ value of $p$ $\leq 0.05)$. Numbers of genes up and down are indicated.

Figure 3. Enriched proportion of ILC1 within papilloma-associated NKp46 ${ }^{+}$cells.

(a) Heatmap representation showing median-centered expression values of selected NK and ILC core genes (Robinette et al., 2015) in $\mathrm{NKp} 46^{+}$cells purified from papillomas, tumors and control skin. (b) Relative proportions of NK cells, ILC1 and ILC3 determined by CIBERSORT analysis. (c-d) Proportions of Eomes ${ }^{+}$cells and CD127 ${ }^{+}$cells among CD3- NKp46 $^{+}$cells. Histogram bars represent the results from three independent experiments, expressed as mean values \pm SEM, $\mathrm{n}=20$ mice per group. ${ }^{*} \mathrm{p}<0.05,{ }^{* *} \mathrm{p}<0.01$, Mann-Whitney U test.

Figure 4. NKp46 ${ }^{+}$cells display decreased cytotoxicity and IFN- $\gamma$ production together with the increased secretion of inflammatory cytokines by ILC1 at papilloma stage.

(a-b) Frequencies of NKp46 ${ }^{+}$cells secreting IFN- $\gamma$ on in vitro stimulation with (a) IL-12+ and IL-18 cytokines, (b, left panel) with PMA and ionomycin. (b, right panel) Frequencies of $\mathrm{NKp}_{4} 6^{+}$cells degranulating upon PMA/ionomycin stimulation. (a-b) Mean values \pm SEM of four independent experiments (each individual value=pool of 5 mice, $n=20$ /group), ${ }^{*} \mathrm{p}<0.05$, Mann-Whitney $U$ test; n.s, not significant. (c) Hierarchical clustering of the genes associated with cytotoxicity. (d) Frequencies of TRAIL, granzymes A and B expressing cells in EOMES $^{+} \mathrm{NKp} 46^{+}$cells (NK cells) and EOMES${ }^{-} \mathrm{NKp}_{4} 6^{+}$cells (ILC1). Mean values $\pm \mathrm{SEM}$, ${ }^{*} \mathrm{p}<0.05, \quad{ }^{*} \mathrm{p}<0.01, \quad * * * \mathrm{p}<0.001, \quad * * * \mathrm{p}<0.0001, \quad$ Two-way ANOVA, Tukey test. (e) Hierarchical clustering of cytokine genes. (f) Frequencies of cytokine-secreting NK cells and ILC1 upon PMA and ionomycin stimulation. Mean values \pm SEM, ${ }^{*} \mathrm{p}<0.05$, Two-way ANOVA, with Tukey posthoc test. 
Figure 5. Differential expression of activating/inhibitory receptors expressed by NK cells and ILC1 infiltrating mouse cSCC.

(a) Hierarchical clustering of activating and inhibitory receptor genes with a minimum log2 average expression of 6 . (b) Heterogeneity of $\mathrm{CD}^{-} \mathrm{NKp}^{-} 6^{+}$cells in mSCC38 carcinoma assessed by t-SNE dimensional reduction using CD49b, CD49a, PD-1, TIM-3, LAG-3, CTLA4 markers and the proportions of manually gated NK cells and ILC1populations. (c-d) Proportions of gated NK cells and ILC1 expressing CD28, CD96 and/or DNAM-1 (c) or NKG2D or TIGIT (d) in mSCC38 carcinoma, ${ }^{*} \mathrm{p}<0.05,{ }^{* *} \mathrm{p}<0.01,{ }^{* * *} \mathrm{p}<0.001$, One-way ANOVA, Kruskal-Wallis test.

Figure 6. Infiltration of human cSCCs with heterogeneous subsets of NK cells and ILCs. (a-b) The frequencies of indicated NK cells and ILC populations in human cSCC biopsies, mean values \pm SEM, (a) $n=9$, (b) $n=14$. (c) NK and ILC heterogeneity assessed by t-SNE dimensional reduction using CD56, NKp46, CD127, CD161, TIGIT, TIM-3 and PD-1 markers $(n=7)$. (d) Cell density for the merged file of healthy distant skin (green), perilesional skin (purple) and tumor (red) samples shown on a black to yellow heat scale. (e) Hierarchical clustering of NK and ILC FlowSOM meta-clusters (MC) depicted in a heatmap of MC cell proportions. (f) Tumor-specific MC groups (red, purple, blue and green arrows) shown in (e) and corresponding groups back-viewed on a t-SNE-1/t-SNE-2 map in (f) with their frequencies for each sample, ${ }^{*} \mathrm{p}<0.05$, ${ }^{* *} \mathrm{p}<0.01$, one-way ANOVA, Kruskal-Wallis test. 
Figure 1

a

DMBA/PMA tumor model
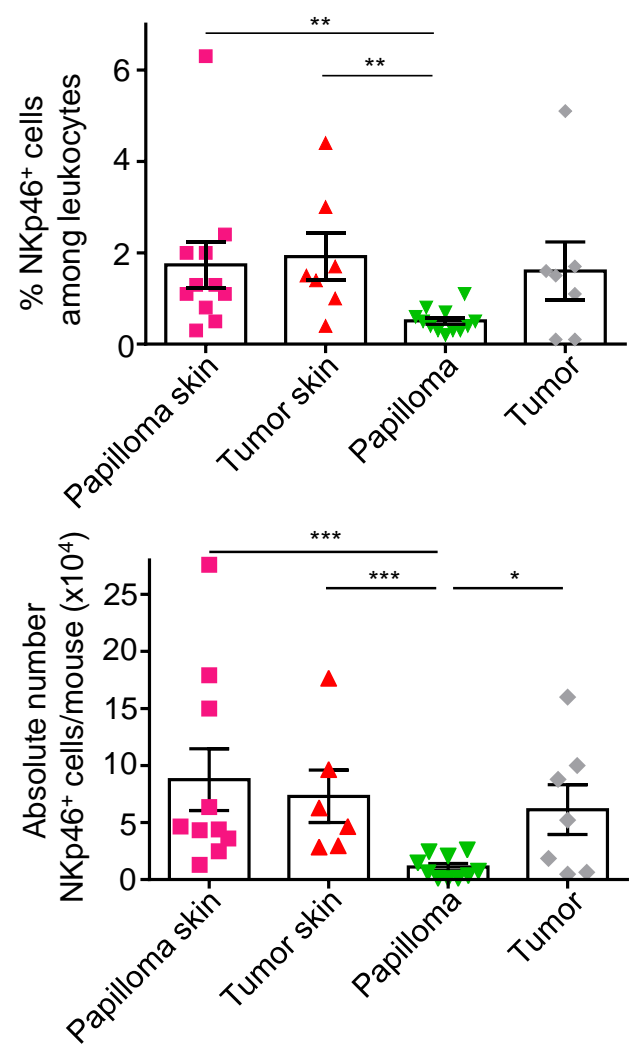

C

DMBA/PMA tumor model

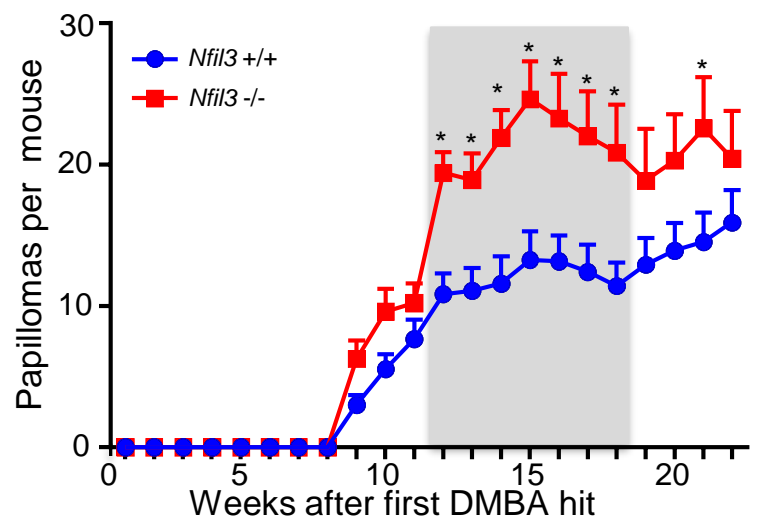

b mSCC38 tumor model
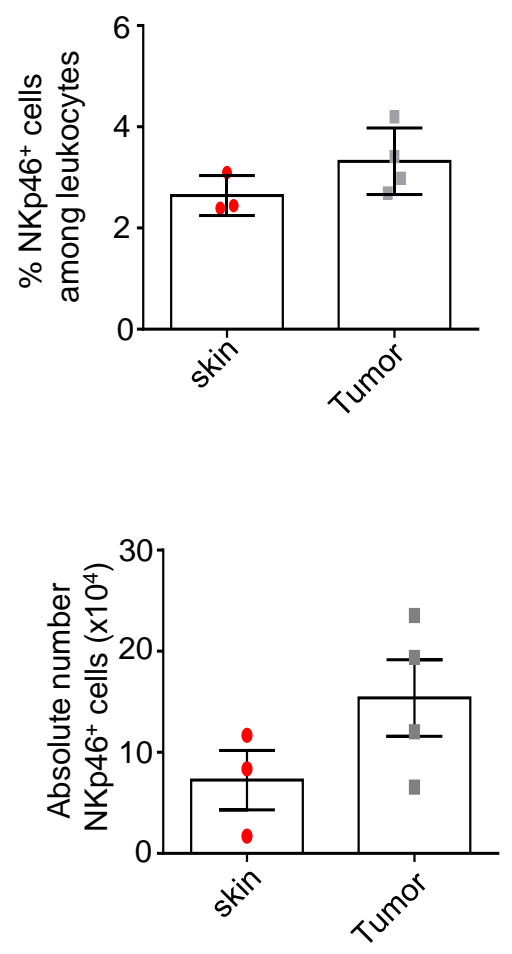

d
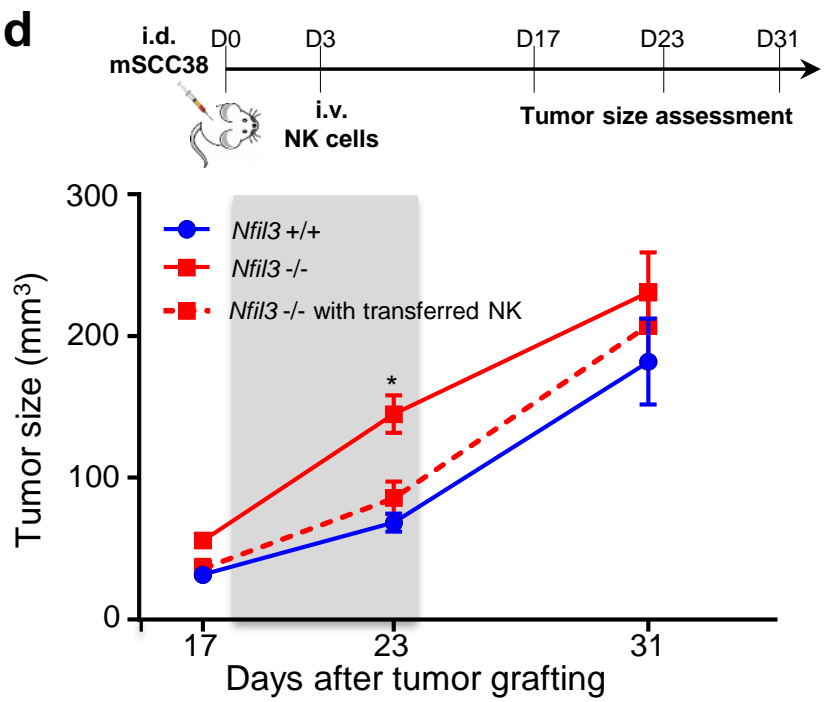
Figure 2

a
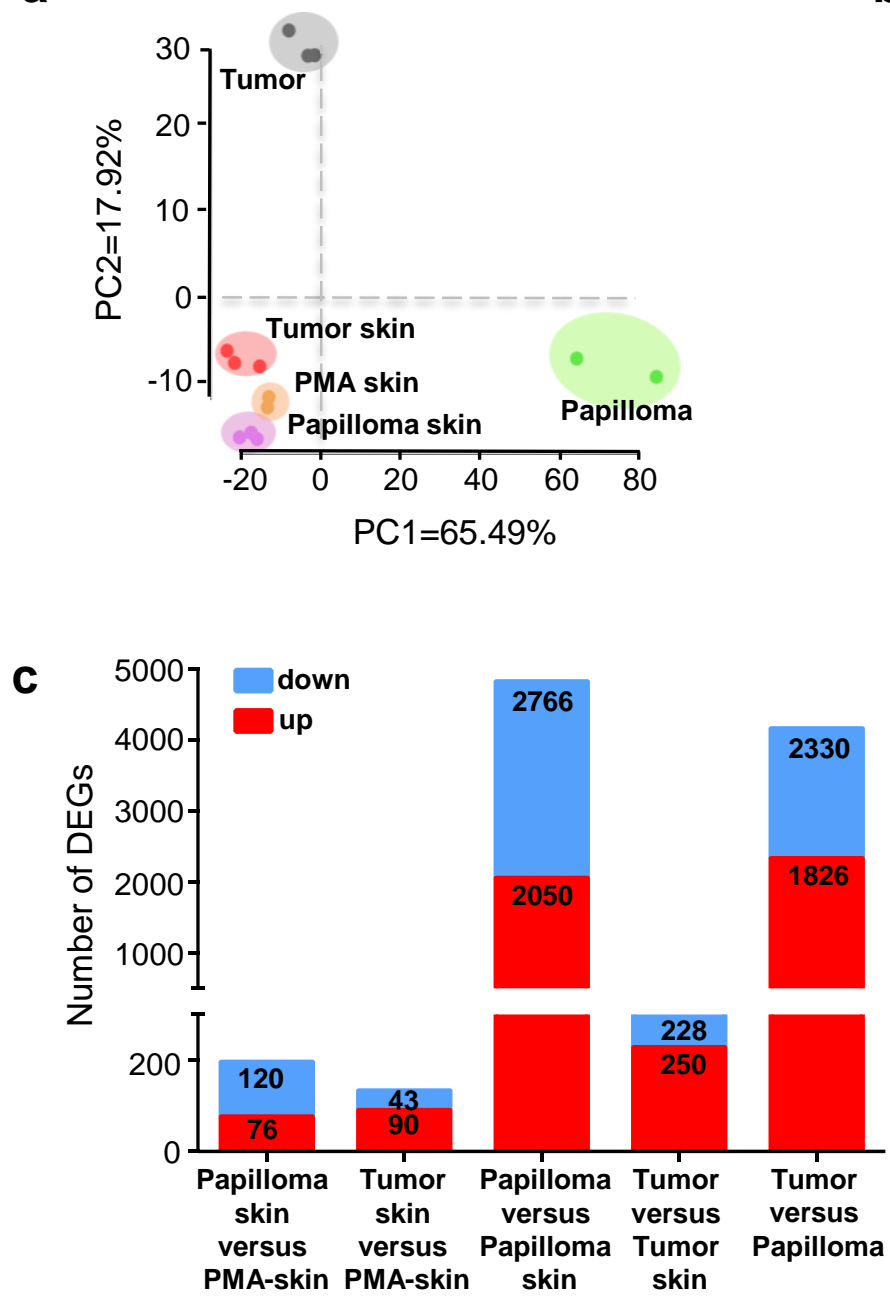

b
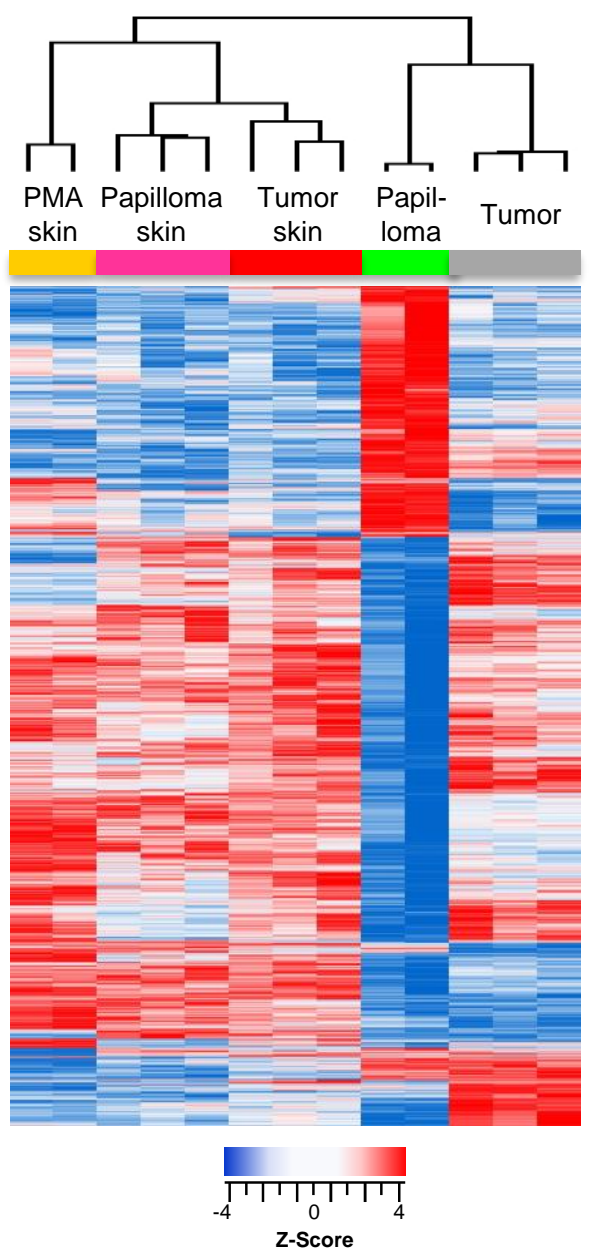
Figure 3

$\begin{array}{cccc}\text { PMA } & \text { Papilloma } & \text { Tumor } & \text { Papil- } \\ \text { skin } & \text { skin } & \text { skin } & \text { loma }\end{array}$

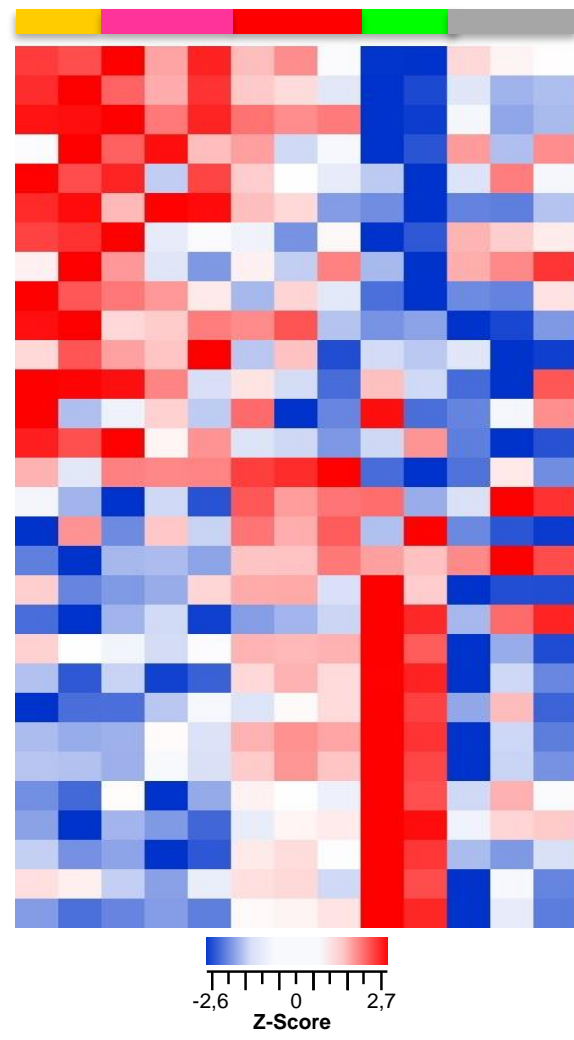

KIra10

KIra9

KIrg1

Irf8

Zeb2

Eomes

Khdc1

Cmklr1

Cym

A430084P05Rik

Itgam

Serpinb9b

KIra1

Socss 2

St6galnac3

Atp8a2

Podnl1

Tmem154

Ckb

Cdon

Grp114

Slc27a6

Tmem176b

Tmem176a

II2ra

Gpr97

Tcrg-V1

IL7r

Cxcr6

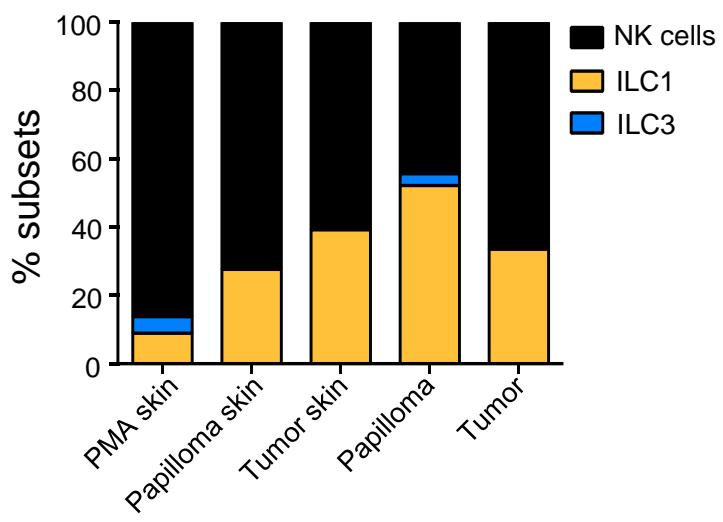

C

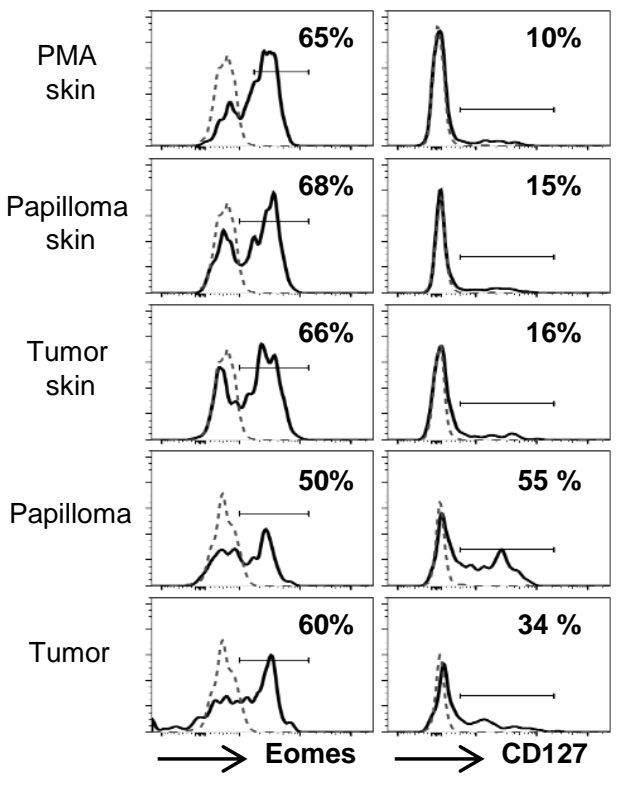

d

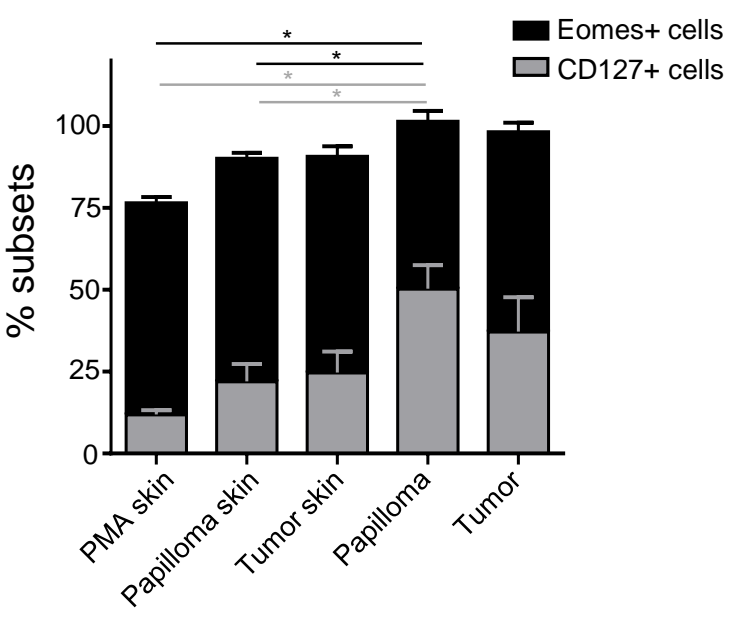




\section{Figure 4}

a

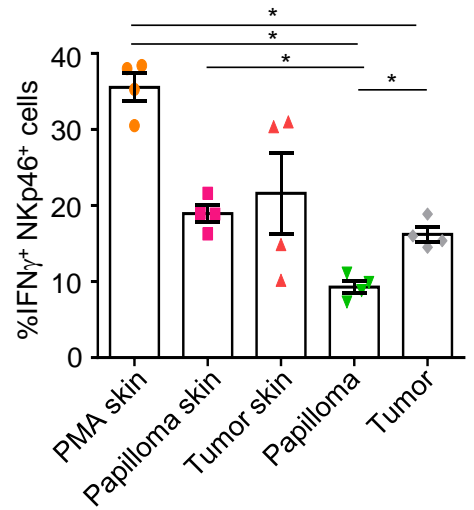

C
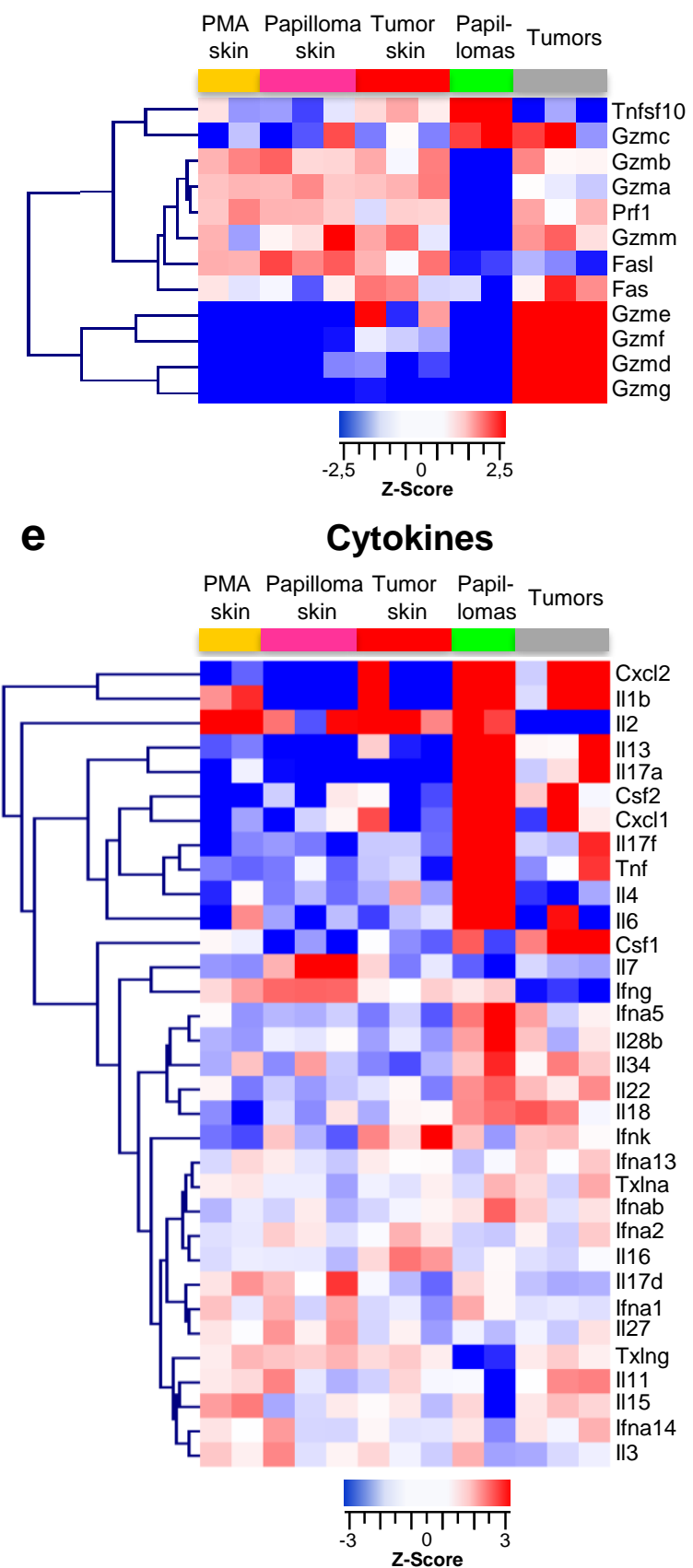

b

PMA+lonomycin
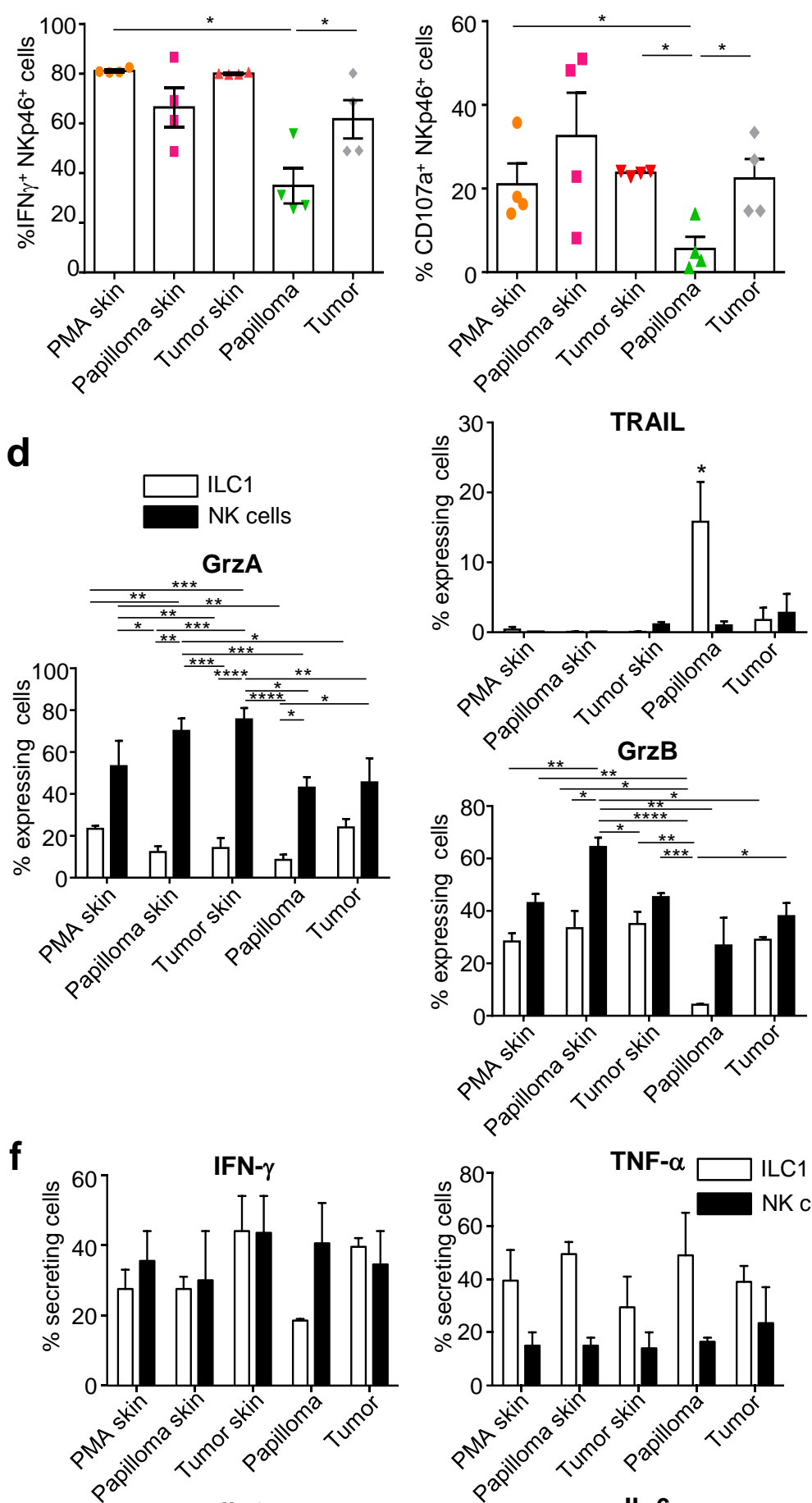

IL-2
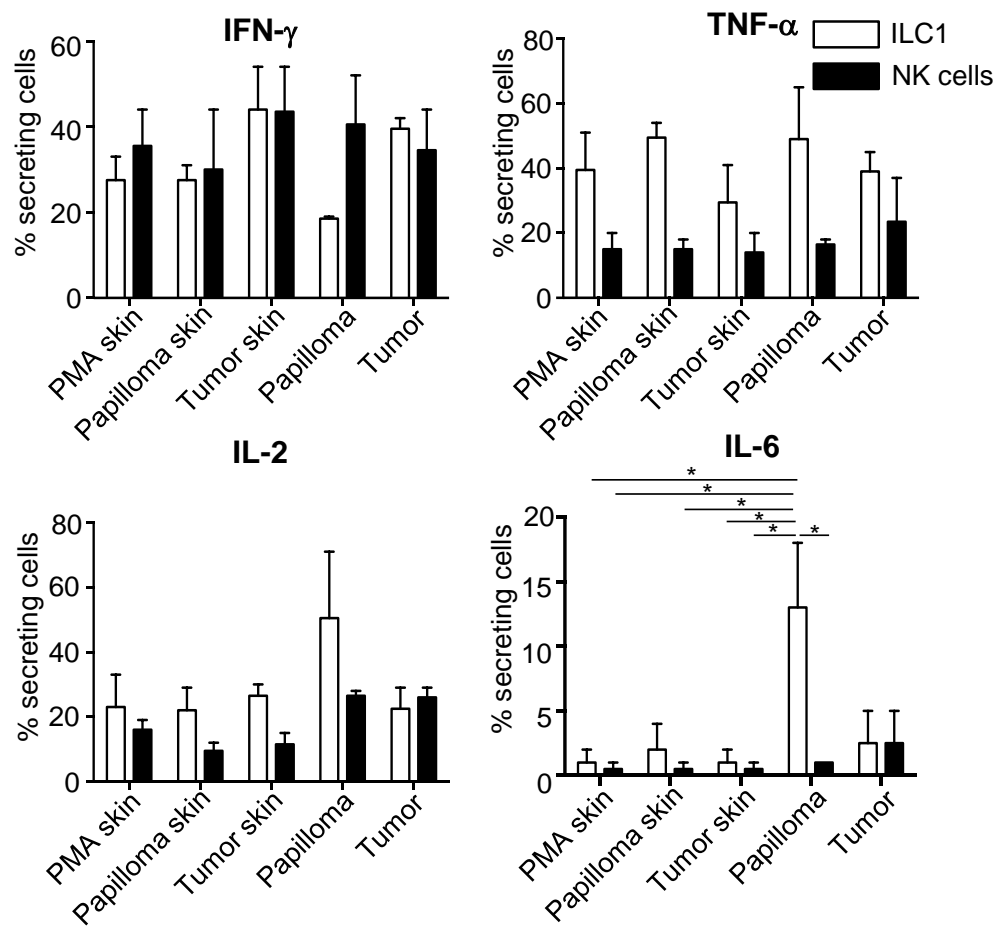


\section{Figure 5}

a

\section{Activating/inhibitory receptors}

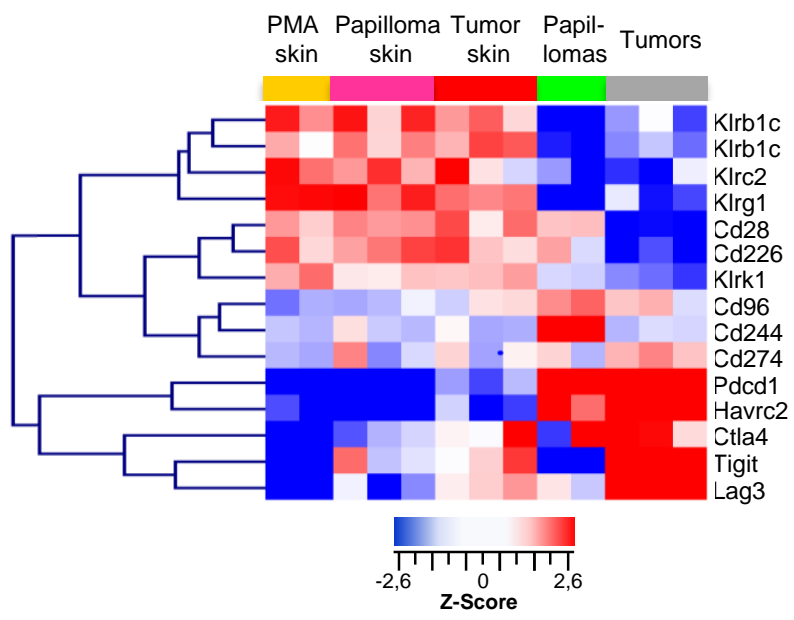

b

Gated on CD3-NKp46+ live NK ILC
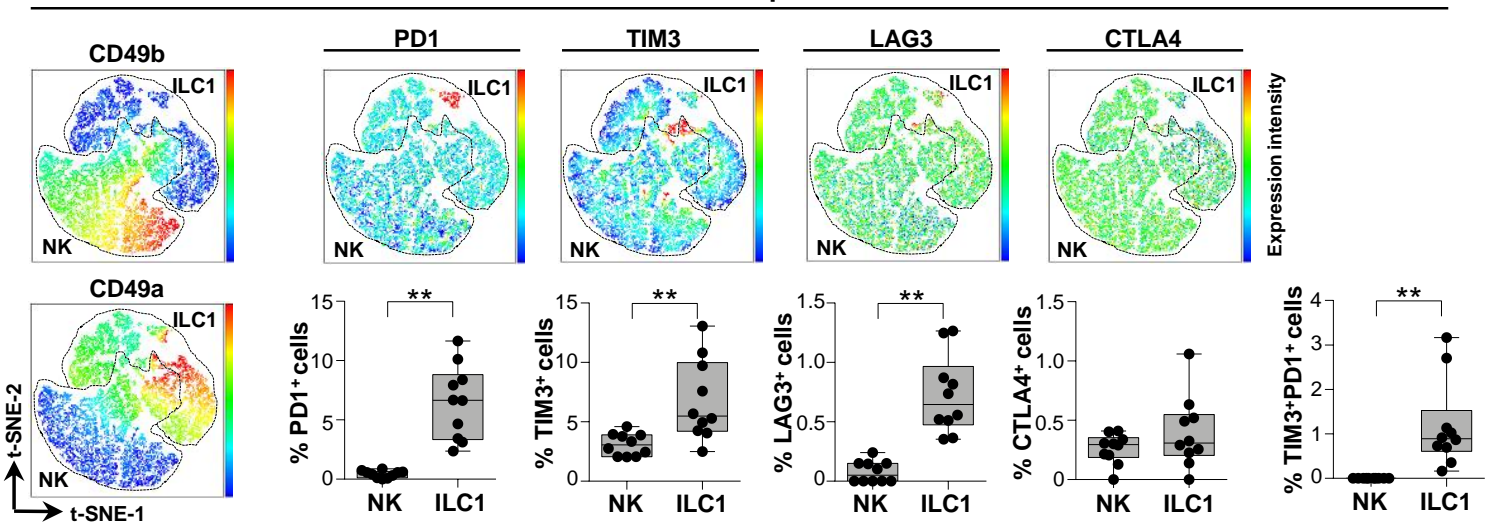

C
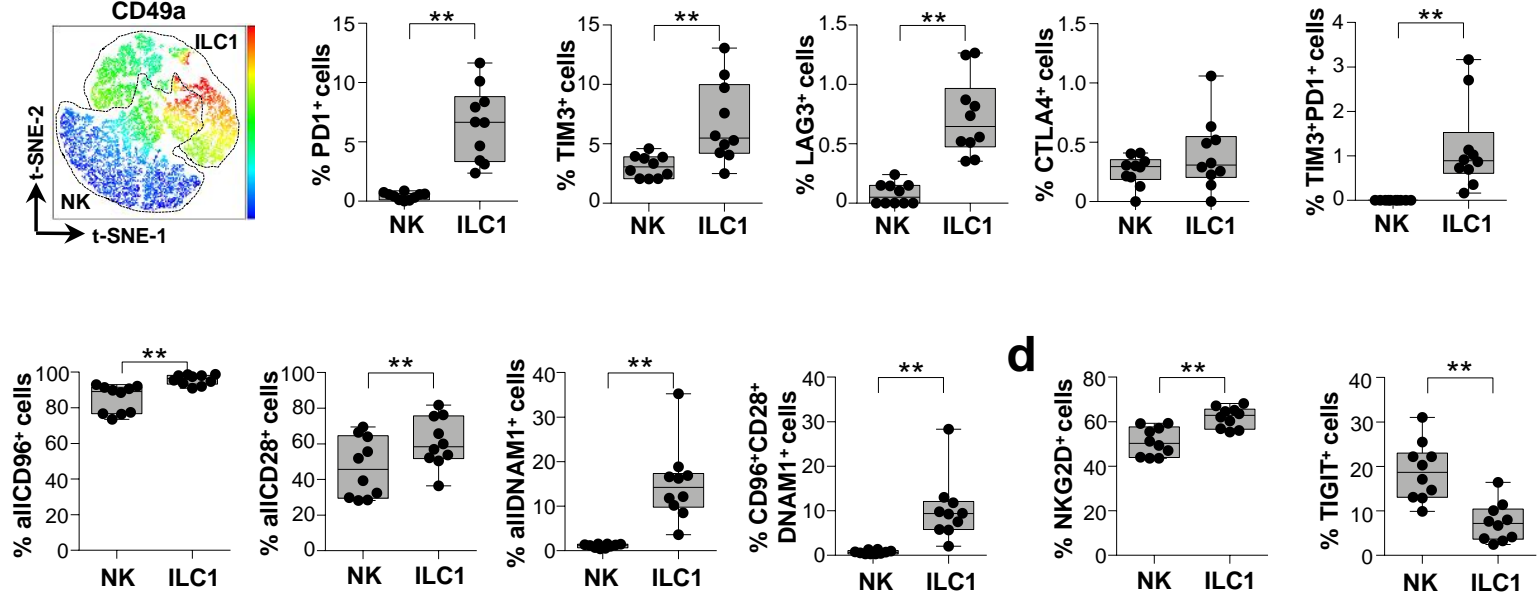
Figure 6

a

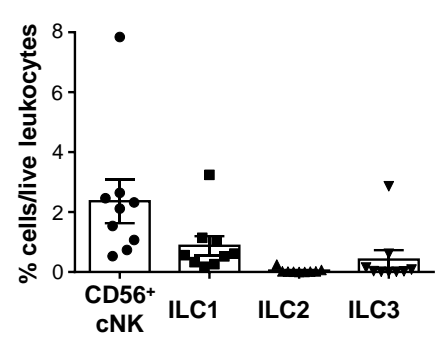

b

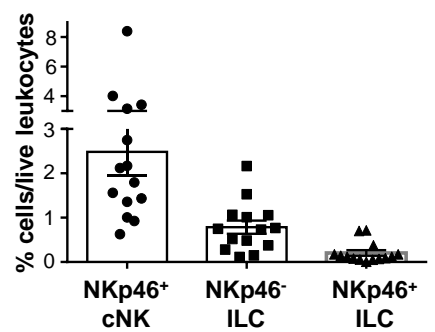

C

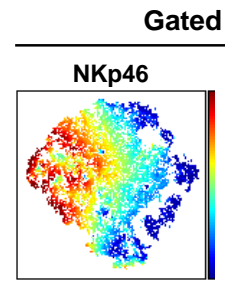

TIGIT
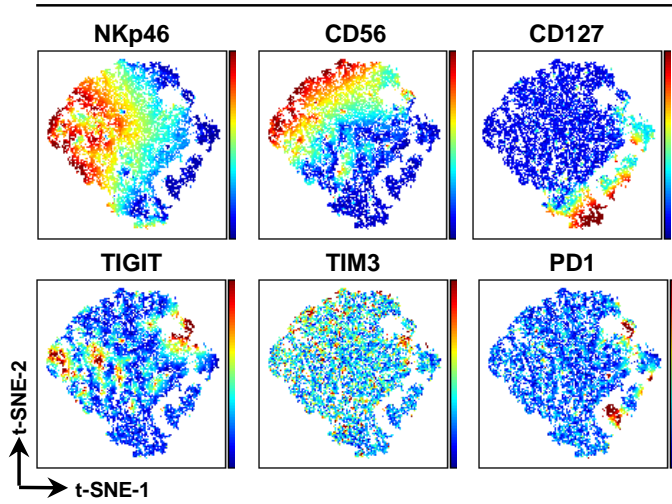

PD1

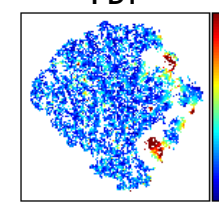

d

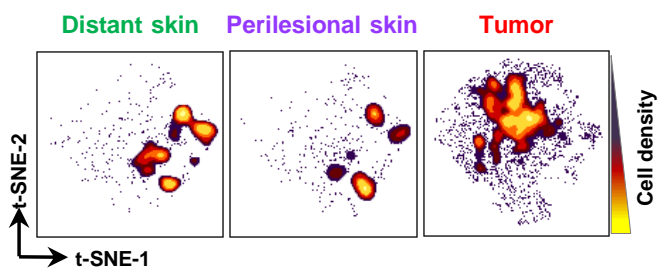

e

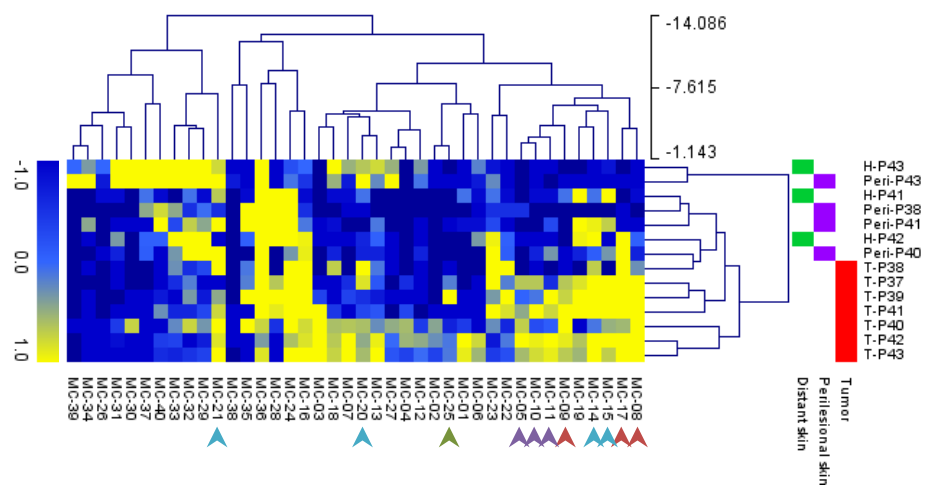

f

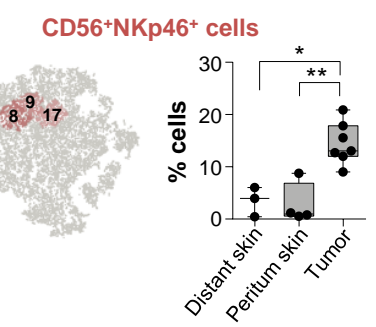

CD56+NKp46/ow/-

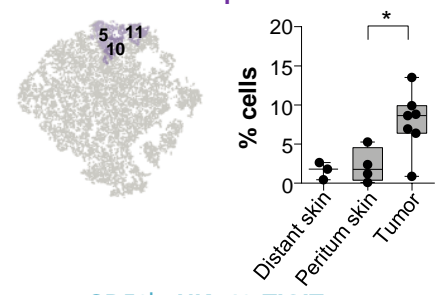

CD56lowNKp46+TIGIT+

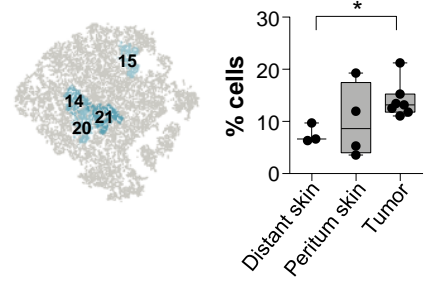

CD56+NKp46-TIGIT+PD1+TIM3+

25

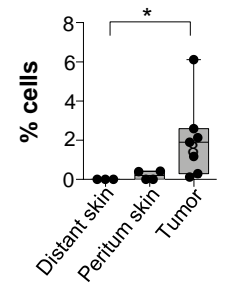




\section{Cutaneous Squamous Cell Carcinoma Development is Associated with a Temporal Infiltration of ILC1 and NK Cells with Immune Dysfunctions}

Luci $\mathrm{C}^{1, \mathrm{a}, *}$,, Bihl $\mathrm{F}^{1, *}$, Bourdely $\mathrm{P}^{1, \mathrm{~b}}$, Khou $\mathrm{S}^{1 \mathrm{c}}$, Popa $\mathrm{A}^{1, \mathrm{~d}}$, Meghraoui-Kheddar $\mathrm{A}^{1}$, Vermeulen $\mathrm{O}^{1}$, Elaldi $\mathrm{R}^{1,2}$, Poissonnet $\mathrm{G}^{2}$, Sudaka $\mathrm{A}^{3}$, Bozec $\mathrm{A}^{2}$, Bekri $\mathrm{S}^{1, \mathrm{e}}$, Cazareth $\mathrm{J}^{1}$, Ponzio $\mathrm{G}^{1}$, Barbry $\mathrm{P}^{1}$, Rezzonico $\mathrm{R}^{1}$, Mari $\mathrm{B}^{1}$, Braud $\mathrm{VM}^{1}$ and Anjuère $\mathrm{F}^{1, \S}$.

\section{SUPPLEMENTARY MATERIALS AND METHODS}

\section{Supplementary materials and methods}

\section{Mice and Mouse tumor models}

Six week-old FVB/N female mice were purchased from Charles River Laboratories (St Germain Nuelles, France). Nfil3-/- deficient mice on FVB/N background and WT littermate controls were produced in house. Briefly, $\mathrm{Nfil3}^{-/-}$knock-out mice were originally on a C57BL/6J background (Gascoyne et al., 2009). They were backcrossed over 21 generations and finally intercrossed in house to produce FVB/N Nfil3/-- mice and wild-type littermate controls. All the experiments have been approved by the regional committee for animal experimentation (NCE/2013-86 and MESR 2018081018546379, Ciepal, Nice Côte d’Azur).

For the two-hit DMBA mouse skin carcinogenesis model, mice were shaved on their back with electric clippers, anesthetized and topically treated twice, week 1 (day 1) and week 7 (day 50) either with the carcinogen 7,12-dimethylbenz[a]anthracene (DMBA, 200 nmol, Sigma-Aldrich, St Quentin Fallavier, France) diluted in acetone or with acetone. In addition, mice received topical administration twice a week, from week 2 to week 20 of the tumor promoter phorbol 12-myristate 13-acetate (PMA, 5 nmol, Sigma-Aldrich). For the orthotopic model, mSCC38 tumor cell line, established from DMBA/PMA induced cSCC (Gastaldi et al., 2014), was maintained in DMEM (Gibco-ThermoFisher Scientific, Courtaboeuf, France) supplemented with 10\% heat-inactivated fetal bovine serum (FBS) (GE Healthcare, Chicago, Illinois, USA), 
penicillin (100 U/ml) and streptomycin (100 $\mu \mathrm{g} / \mathrm{mL})$ (Gibco-ThermoFisher Scientific). 5 x $10^{5}$ mSCC38 were intra-dermally injected in anesthetized mice after dorsal skin shaving. Tumor volume was calculated according to the ellipsoid formula Volume $=$ Length $(\mathrm{mm}) \times$ Width $(\mathrm{mm})$ $\times$ Height $(\mathrm{mm}) \times(\pi / 6)$

\section{NK cell transfer experiments}

Splenic NK cells were enriched from six week-old FVB/N female mice by immunomagnetic cell-sorting after staining with the NK Cell Isolation Kit according to the manufacturer's instructions (Miltenyi, Bergisch Gladbach, Germany). NK cell purity was checked by flow cytometry after staining with anti-NKp46 and anti-CD49b antibodies (Supplementary Figure 1f). 500000 isolated splenic NK cells were injected intraveinously into mSSC38 tumor-bearing $N f i l^{3-/-}$ mice on day 3 post-grafting.

\section{Patient biopsies}

cSCC biopsies, perilesional and distant skins were obtained from patients who underwent surgical excision at the Centre Antoine Lacassagne (CAL, Nice, France) and who signed an informed consent according to the Declaration of Helsinki under CAL institutional review board approval.

\section{Tissue histology}

Skin, papilloma and carcinoma samples from DMBA/PMA treated mice were fixed in 10\% neutral buffered formalin and embedded in paraffin using standard protocol. FFPE blocks were sectioned at $5 \mu \mathrm{m}$, and stained with H\&E.

\section{Cell preparations}


Dorsal mouse skins were prepared by mechanical dilaceration in small pieces followed by two successive enzymatic treatments with collagenase IV $(0.6 \mathrm{mg} / \mathrm{mL})$ (Sigma-Aldrich) at $37^{\circ} \mathrm{C}$ for 20 minutes under constant shaking. Papilloma and tumor tissues were cut in small pieces and then treated with collagenase IV (1 mg/mL) (Sigma-Aldrich), dispase II (2.5 mg/mL) and DNase $(0.2 \mathrm{mg} / \mathrm{mL})$ (Roche Diagnostics, Meylan, France) at $37^{\circ} \mathrm{C}$ for 20 minutes under constant shaking. Skin, papilloma or tumor cell samples were then enriched in immune cells by Percoll gradient centrifugation (GE Healthcare). Mouse CD3 ${ }^{-} \mathrm{KN}^{4} 6^{+}$immune cells were sorted on a Becton Dickinson FACS Aria III. After mechanical dilaceration, human tumor biopsies were digested with collagenase IV from Clostridium histolyticum $(1,25 \mathrm{mg} / \mathrm{mL})$ and DNAse II-S from bovine pancreas $(0,13 \mathrm{mg} / \mathrm{mL})$ (Sigma-Aldrich) at $37^{\circ} \mathrm{C}$ for 40 minutes under constant shaking. Cell suspensions were filtered through a $70 \mu \mathrm{m}$ cell strainer to eliminate aggregates.

\section{Flow cytometry and computational analysis}

Flow cytometry stainings with the antibodies listed in Supplementary Table S5 were performed on mouse cells preincubated with purified anti-Fc $\gamma$ RII/III mAb (clone 2.4G2) (BD Biosciences, Le Pont de Claix, France) at $4^{\circ} \mathrm{C}$ for 10 minutes to block Fc receptors. Intracellular satinings were performed using Foxp3 fixation/permeabilization kit (eBiosciences). Flow cytometry surface stainings were performed on human cells from biopsies preincubated with mouse serum (1/10) (Biowest, Nuaille, France) and IgG from human serum (100 $\mu \mathrm{g} / \mathrm{mL})$ (Sigma-Aldrich) 30 minutes at $4^{\circ} \mathrm{C}$ to prevent unspecific binding. The antibodies used for human cell stainings are listed in Supplementary Table S6. Isotype-matched control monoclonal antibodies were used to insure the specificity of the stainings. Data were acquired on a BD LSRII Fortessa and analyzed with FlowJo V10 software (BD Biosciences) and cytobank platform (Beckman Coulter). The t-Distributed Stochastic Neighbor Embedding (t-SNE) was used to automatically 
arrange NK cells and ILC subsets, from mouse and human samples, according to their expression profile of the measured proteins, in a 2-D map defined by t-SNE1 and t-SNE-2 axes. For the human samples, after dimensionality reduction with t-SNE, NK cells and ILC subsets were separated into 40 meta-clusters (MC) using FlowSOM automatic clustering. Samples and mean-centered Log2-transformed MC cell proportions were depicted in a heatmap and arranged according to complete linkage hierarchical clustering.

\section{Functional assays}

Cells were plated in U-bottomed 96-well plates (BD Biosciences) and were incubated at $37^{\circ} \mathrm{C}$ for 4 hours in the presence of either PMA (100 ng/mL) and ionomycin (1 $\mu \mathrm{g} / \mathrm{mL})$ (SigmaAldrich) or mouse IL-12 (20 ng/mL; Bio-Techne, Lille, France) and mouse IL-18 (5ng/mL; Clinisciences). Degranulation activity was assessed by addition of Fluorescein isothiocyanateconjugated anti-mouse CD107a (1D4B) and GolgiStop (BD Biosciences) at the beginning of cell stimulation. Cytokine secretion was evaluated by intracellular staining after PMA and ionomycin stimulation for 4 hours in presence of GolgiStop and GolgiPlug (BD Biosciences).

\section{RNA extraction and microarrays}

RNA was extracted from $10^{4}$ to $5 \times 10^{5}$ cells for each sorted immune cell subset using the micro RNAeasy kit (Qiagen, Courtaboeuf, France), yielding to 50 to 700 ng of total RNA for each sample. Quality and absence of genomic DNA contamination were assessed on a Bioanalyser (Agilent Technologies, Massy, France). RNA from each sample was used to synthesize probes with the LowInput QuickAmp Labeling Kit (Agilent Technologies). cRNA with appropriate quality control were hybridized to SurePrint G3 Mouse GE 8x60K microarrays (Agilent Technologies). 


\section{Microarray data normalization and differential analysis}

The microarray experimental data and associated microarray designs are deposited in the NCBI Gene Expression Omnibus (GEO) (http://www.ncbi.nlm.nih.gov/geo/) under the serial record number GSE84027. The raw data were quantile normalized using the Bioconductor package limma (Diboun et al., 2006). Batch effect induced by the microarray chips was removed using the ComBat method (Johnson et al., 2007). Means of ratios from all comparisons were calculated and the moderated t-statistic of the limma package provided the per gene p-values. The Benjamini-Hochberg procedure was used to control the experiment-wise false discovery rate (FDR) from multiple testing procedures. Differentially expressed probesets were selected based on the following criteria: average $\log 2$ expression level across all conditions $\geq 6$, absolute log2-fold change $\geq 1$, and adjusted $p$-value $\leq 0.05$.

\section{Transcriptomic data analysis}

The analysis of the thirteen transcriptomes corresponding to $\mathrm{NKp} 46^{+}$cells in the five tissues of origin was performed using a principal component analysis approach (PCA) on the $10 \%$ most variable probesets across all samples with a minimum average intensity of 6 . The probesets were selected with the Population Distances program from http://cbdm.hms.harvard.edu/LabMembersPges/SD.html. The PCA was performed in R. For an exploratory hierarchical clustering on the different transcriptomes of NKp46 ${ }^{+}$cells, the probesets with a minimum average intensity of 6 and part of the $10 \%$ most variable probesets across $\mathrm{NKp}_{4} 6^{+}$cell samples (http://cbdm.hms.harvard.edu/LabMembersPges/SD.html) were analyzed. Probesets were median-centered across samples and the chosen clustering method was a pairwise average-linkage (GenePattern) (Reich et al., 2006).

To assess the different cell populations in our samples, wedownloaded the public dataset GSE37448 containing the transcriptomes of NK cells and ILC populations from different 
tissues (Robinette et al., 2015). Data were normalized using quantile normalization (Bioconductor package affy) (Gautier et al., 2004). We focused on NKp46 ${ }^{+}$cell populations on which we defined a specific signature for ILC1, ILC3, and NK cells (Supplementary Table S2). We developed the specific gene signatures based on a difference in expression, between the averages of any two cell types, superior to 1.5 (in log2) and completed with published gene signatures (Robinette et al., 2015). We compared the expression of these signature genes in each one of our NKp46 ${ }^{+}$cells transcriptomes using the CIBERSORT method (Newman et al., 2015). 


\section{Supplementary Figures}

a

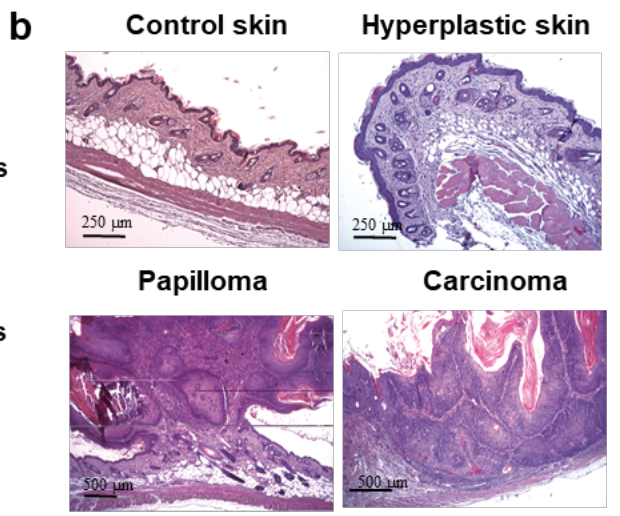

C

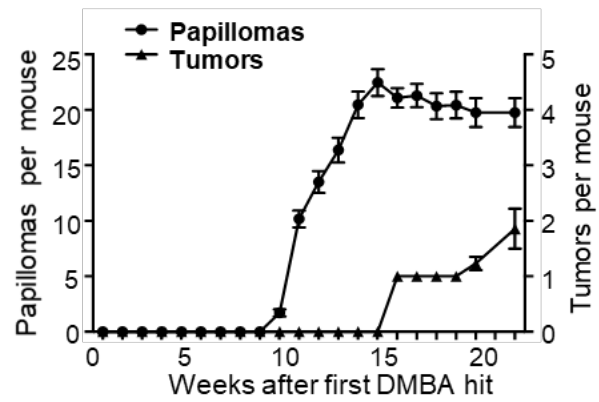

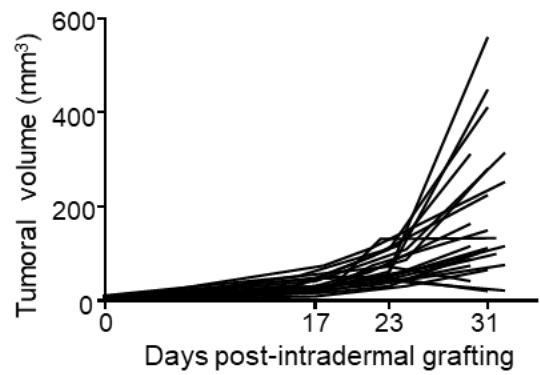

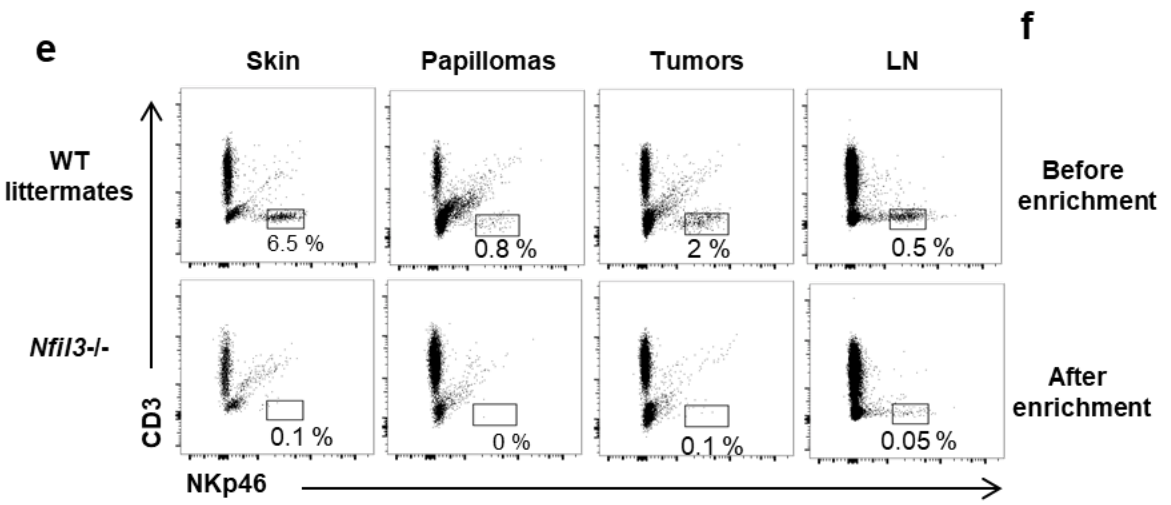

live $\mathrm{CD} 45^{+}$cells

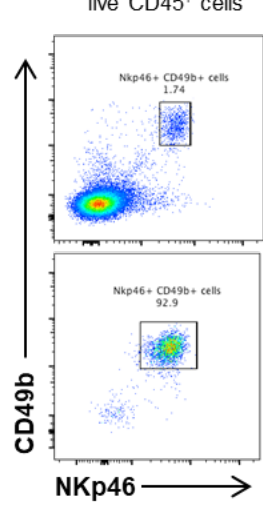

Supplementary Figure 1. DMBA/PMA and mSCC38 mouse models of skin carcinogenesis.

(a) Schematic representation of the two-hit DMBA mouse skin carcinogenesis protocol. (b) Representative hematoxylin/eosin counterstained tissue sections of control skin, hyperplastic skin, papilloma and carcinoma from DMBA/PMA-treated mice. (c) Kinetics of development of papillomas and tumors in FVB/N WT mice upon DMBA/PMA treatment. The numbers of papillomas and tumors per mouse are expressed as mean \pm SEM. Three independent experiments were performed (total $n=100$ mice). (d) Growth kinetic of mSCC38 grafted intradermally in $\mathrm{FVB} / \mathrm{N}$ mice ( $\mathrm{n}=23$ mice). (e) Representative flow cytometry dot plots of $\mathrm{NKp}_{4}{ }^{+} \mathrm{CD}^{-}$among $\mathrm{CD}^{-} 5^{+}$cells. (f) NK cell enrichment from total splenocytes by immunomagnetic cell-sorting before adoptive transfer experiments. 
a

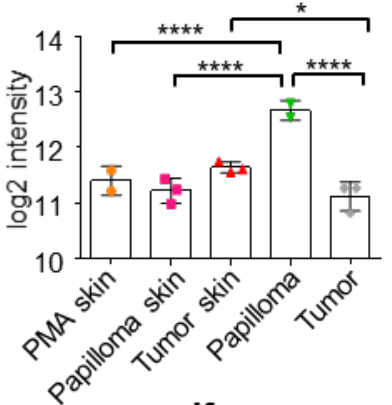

b
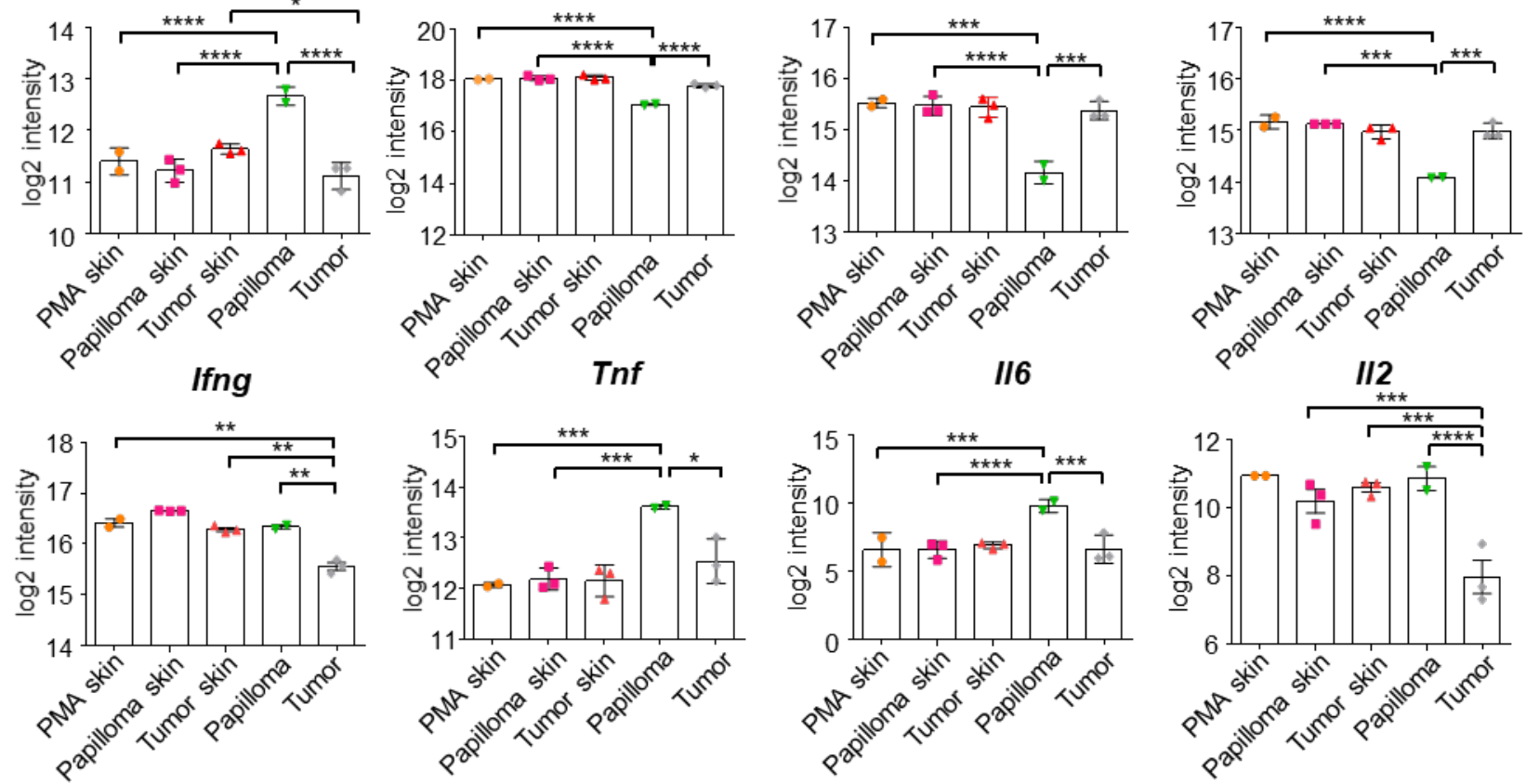

C
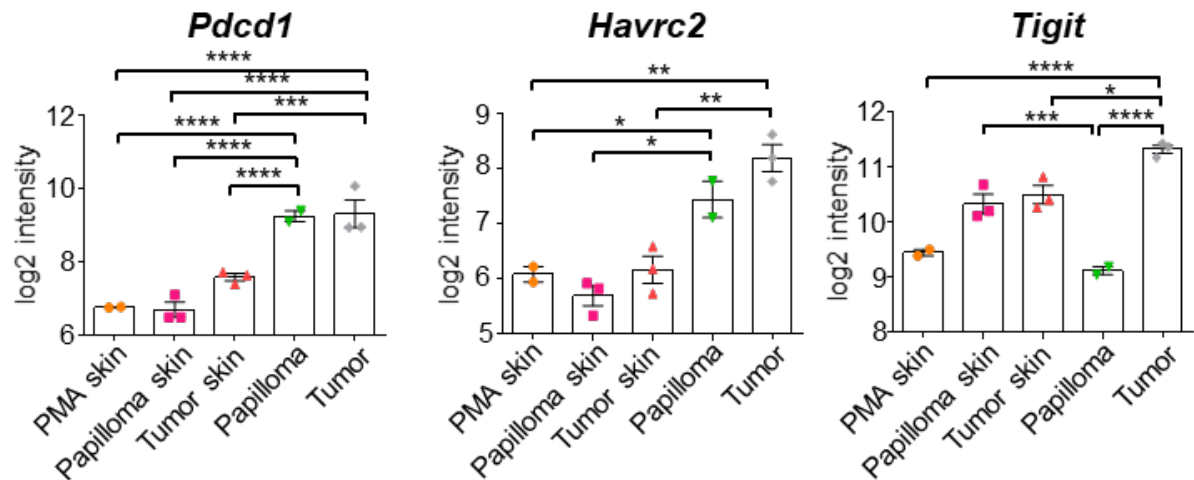

Lag3

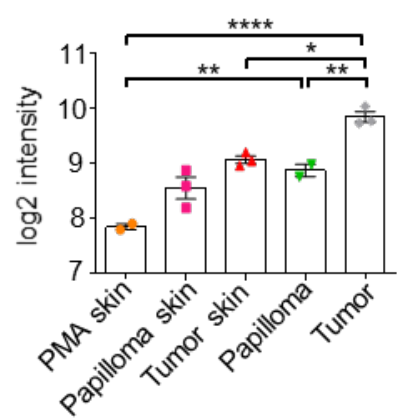

Supplementary Figure 2. Distinct transcriptional signatures of $\mathrm{NKp}^{+}{ }^{+}$cells isolated from cSCC lesions and surrounding skin of DMBA/PMA-treated mice.

Average intensity expression levels and adjusted $p$ values of (a) Tnfs10 (TRAIL), Gzmb (granzyme B), Prf1 (perforin) and Gzma (granzyme a), (b) Tnf, Il6, Il2 and Ifng, (c) Pdcd1, Havrc2, Tigit and Lag3 transcripts are shown, ${ }^{*} p<0.05$, ${ }^{* *} p<0.01,{ }^{* * *} p<0.001,{ }^{* * * *} p<0.0001$, limma differential expression analysis. 
a

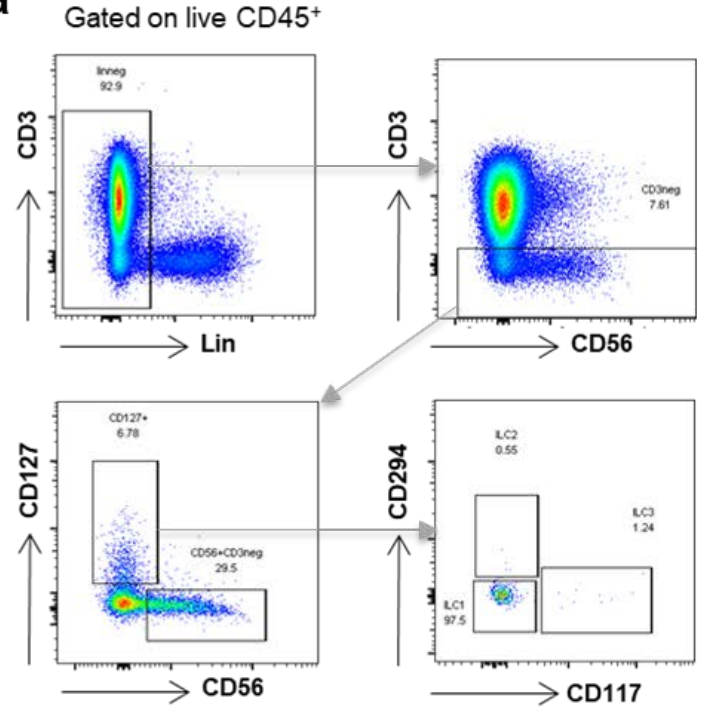

b
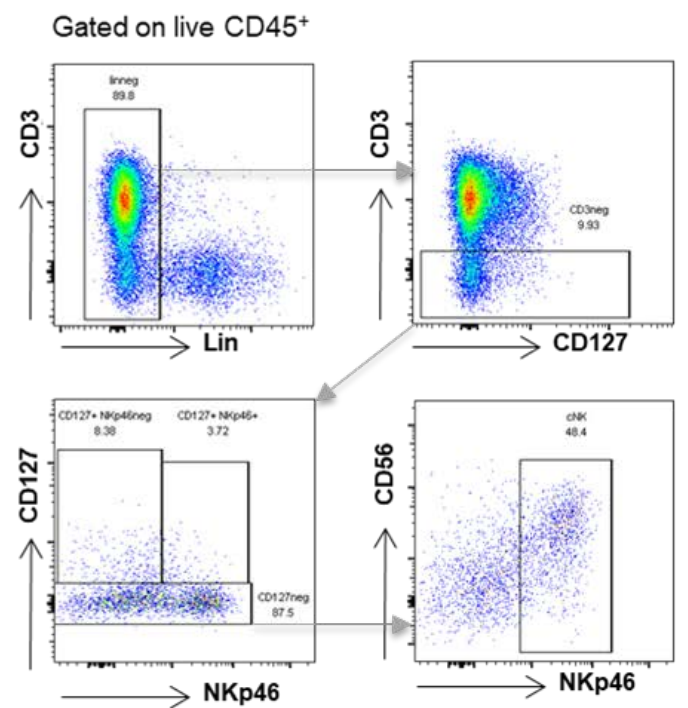

Supplementary Figure 3. Flow cytometry gating strategies for the immune phenotyping of human cSCC biopsies.

Representative flow cytometry dot plots showing the gating strategy to identify (a) $\mathrm{CD}^{2} 6^{+} \mathrm{CD}^{-}$

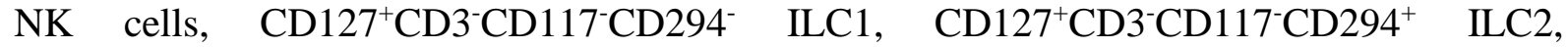
CD $127^{+} \mathrm{CD}^{-} \mathrm{CD} 117^{+} \mathrm{CD} 294^{-}$ILC3 among live CD45 ${ }^{+}$cells and (b) $\mathrm{NKp}^{-} 6^{+} \mathrm{CD}^{-} 6^{+/ \mathrm{dim} \mathrm{CD}^{-}}$ NK cells, NKp46-CD127 ${ }^{+} \mathrm{CD}^{-}$ILC, NKp46 ${ }^{+} \mathrm{CD} 127^{+} \mathrm{CD}^{-}$ILC among live CD $45^{+}$cells from human cSCC biopsies. 


\section{Supplementary Tables}

\section{Supplementary Table 1: Core NK/ILC probesets}

See excel file Supplementary Table S1

Supplementary Table S2: Core ILC1, ILC3 and NK cells probesets

See excel file Supplementary Table S2

Supplementary Table S3: Expression profiles of genes associated with cytotoxicity, cytokines and activating and inhibitory receptors

See excel file Supplementary Table S3 


\section{Supplementary Table 4: Patients' characteristics}

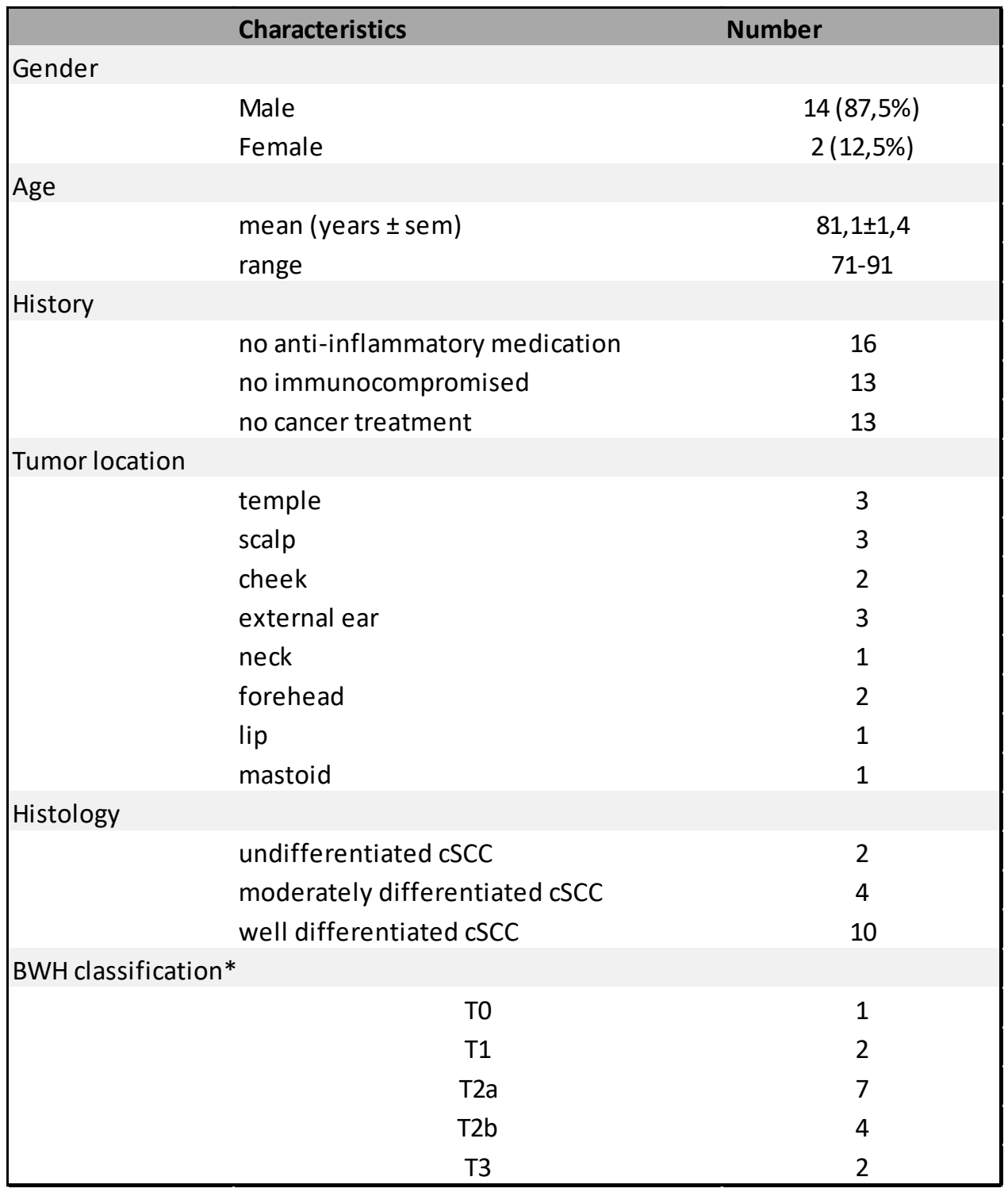

*Brigham and Women's Hospital tumor classification system: classification system based on risk factors specific for cSCC (Jambusaria-Pahlajani et al., 2013). Risks factors include tumor diameter of $2 \mathrm{~cm}$ or larger, poorly differentiated histology, perineural invasion and tumor invasion beyond the subcutaneous fat (excluding bones which automatically upgrades to T3). 
Supplementary Table S5: Mouse antibodies

\begin{tabular}{|c|c|c|}
\hline Markers & Clone & Provider \\
\hline \multicolumn{3}{|c|}{ Fc receptors blocking } \\
\hline FcgRII/III & $2.4 \mathrm{G} 2$ & BD Biosciences \\
\hline \multicolumn{3}{|l|}{ Surface staining } \\
\hline CD45 & 30-F11 & BD Biosciences \\
\hline CD127 & A7R34 & eBiosciences \\
\hline CD226 & $10-\mathrm{E} 5$ & Biolegend \\
\hline $\mathrm{CD} 28$ & 37.51 & BD Biosciences \\
\hline CD3e & $145-2 \mathrm{C} 11$ or $500 \mathrm{~A} 2$ & BD Biosciences \\
\hline CD49a & $\mathrm{Ha} 31 / 8$ & BD Biosciences \\
\hline $\mathrm{CD} 49 \mathrm{~b}$ & DX5 & BD Biosciences \\
\hline CD96 & 3.3 & Biolegend \\
\hline CTLA-4 & UC10-4F10-11 & BD Biosciences \\
\hline LAG-3 & C9B7W & BD Biosciences \\
\hline NKp46 & 29A1.4 & BD Biosciences \\
\hline PD-1 & $\mathrm{J} 43$ & BD Biosciences \\
\hline TIGIT & $1 \mathrm{G9}$ & BD Biosciences \\
\hline TIM-3 & $5 \mathrm{D} 12$ & BD Biosciences \\
\hline TRAIL & $\mathrm{N} 2 \mathrm{~B} 2$ & eBiosciences \\
\hline \multicolumn{3}{|c|}{ Intracellular staining } \\
\hline Eomes & Dan11mag & eBiosciences \\
\hline Granzyme A & $3 G 8.5$ & Clinisciences \\
\hline Granzyme B & NGZB & eBiosciences \\
\hline IFN-g & XMG1.2 & BD Biosciences \\
\hline IL-2 & JES6-5H4 & BD Biosciences \\
\hline IL-6 & MP5-20F3 & BD Biosciences \\
\hline TNF-a & MPX-XT22 & BD Biosciences \\
\hline
\end{tabular}

Supplementary Table S6: Human antibodies

\begin{tabular}{|lll|}
\hline \multicolumn{1}{c}{ Markers } & \multicolumn{1}{c|}{ Clone } & \multicolumn{1}{c|}{ Provider } \\
Surface staining & & \\
CD127 & HIL 7R M21 & BD Biosciences \\
CD14 & M5E2 & BD Biosciences \\
CD15 & HI98 & BD Biosciences \\
CD161 & 191B8 & Myltenyi Biotec \\
CD19 & HIB19 & eBiosciences \\
CD3 & SK7 & BD Biosciences \\
CD45 & HI30 & BD Biosciences \\
CD56 & B159 & BD Biosciences \\
LAG3 & TA47-530 & BD Biosciences \\
NKp46 & & Beckman Coulter \\
PD-1 & EH12.2H7 & Biolegend \\
TIGIT & A15153G & Biolegend \\
TIM3 & F38-2E2 & Biolegend \\
\hline
\end{tabular}




\section{Supplementary Table 1}

\begin{tabular}{|c|c|c|c|c|c|c|c|c|c|c|c|c|c|c|}
\hline \multicolumn{2}{|l|}{ Raw data Table } & \multicolumn{2}{|c|}{ PMA skin } & \multicolumn{3}{|c|}{ Papilloma skin } & \multicolumn{3}{|c|}{ Tumor skin } & \multicolumn{2}{|c|}{ Papilloma } & \multicolumn{3}{|c|}{ Tumor } \\
\hline GeneName & Description & PMA_skin_1 & PMA_skin_2 & Papilloma_skin_1 & Papilloma_skin_2 & Papilloma_skin_3 & Tumor_skin_1 & r_skin_2 1 & Tumor_skin_3 & Papilloma_1 Pa & pilloma_2 & Tumor_1 & Tumor_2 & Tumor_3 \\
\hline KIra10 & NK & 9.10 & 9.04 & 9.29 & 8.76 & 9.18 & 8.67 & 8.83 & 8.43 & 6.56 & 6.53 & 8.59 & 8.49 & 8.47 \\
\hline Klra9 & NK & 13.01 & 13.20 & 12.76 & 12.44 & 12.98 & 12.30 & 12.22 & 11.89 & 10.47 & 10.64 & 11.88 & 11.48 & 11.56 \\
\hline KIrg1 & NK & 13.55 & 13.57 & 13.61 & 13.26 & 13.51 & 13.28 & 13.21 & 13.26 & 11.36 & 11.44 & 12.82 & 12.23 & 12.38 \\
\hline Irf8 & NK & 15.14 & 15.63 & 15.45 & 15.61 & 15.27 & 15.33 & 15.00 & 15.13 & 14.33 & 14.46 & 15.34 & 14.89 & 15.37 \\
\hline Car5b & NK & 8.65 & 8.51 & 8.58 & 7.90 & 8.52 & 8.26 & 8.16 & 8.06 & 7.88 & 7.06 & 8.02 & 8.41 & 8.12 \\
\hline Zeb2 & NK & 7.71 & 7.77 & 7.41 & 7.79 & 7.77 & 7.40 & 7.35 & 6.95 & 6.90 & 6.61 & 6.87 & 6.86 & 7.08 \\
\hline Eomes & NK & 12.80 & 12.83 & 12.91 & 12.42 & 12.46 & 12.44 & 12.17 & 12.48 & 11.91 & 12.01 & 12.60 & 12.55 & 12.50 \\
\hline Khdc1a & NK & 6.13 & 6.55 & 6.28 & 6.02 & 5.74 & 6.13 & 5.93 & 6.32 & 5.86 & 5.38 & 6.25 & 6.31 & 6.46 \\
\hline Cmklr1 & NK & 6.89 & 6.70 & 6.63 & 6.56 & 6.39 & 6.17 & 6.43 & 6.29 & 5.99 & 5.85 & 6.06 & 6.04 & 6.40 \\
\hline Cym & NK & 9.68 & 9.72 & 9.17 & 9.20 & 9.40 & 9.37 & 9.51 & 8.87 & 8.71 & 8.77 & 8.39 & 8.46 & 8.73 \\
\hline A430084P05Rik & NK & 12.21 & 12.48 & 12.33 & 12.25 & 12.66 & 12.03 & 12.26 & 11.80 & 12.06 & 12.03 & 12.09 & 11.75 & 11.77 \\
\hline Itgam & NK & 11.36 & 11.36 & 11.34 & 11.21 & 10.99 & 11.09 & 10.99 & 10.74 & 11.14 & 10.98 & 10.73 & 10.61 & 11.26 \\
\hline Serpinb9b & NK & 5.61 & 5.29 & 5.34 & 5.40 & 5.30 & 5.50 & 5.13 & 5.22 & 5.59 & 5.20 & 5.22 & 5.35 & 5.47 \\
\hline Klra1 & NK & 12.17 & 12.05 & 12.25 & 11.63 & 11.88 & 11.52 & 11.48 & 11.28 & 11.48 & 11.87 & 11.20 & 10.96 & 11.06 \\
\hline Socs2 & ILC & 9.42 & 8.96 & 9.63 & 9.60 & 9.61 & 9.89 & 9.97 & 10.14 & 8.06 & 7.64 & 8.10 & 9.21 & 8.29 \\
\hline St6galnac3 & ILC & 6.65 & 6.50 & 6.22 & 6.59 & 6.29 & 6.89 & 6.80 & 6.85 & 6.86 & 6.49 & 6.61 & 7.01 & 6.94 \\
\hline Atp8a2 & ILC & 5.65 & 6.10 & 5.78 & 6.02 & 5.88 & 6.15 & 6.06 & 6.19 & 5.85 & 6.33 & 5.77 & 5.70 & 5.67 \\
\hline Podnl1 & ILC & 9.80 & 9.28 & 10.19 & 10.21 & 10.05 & 10.89 & 10.89 & 11.18 & 11.03 & 10.91 & 11.12 & 11.66 & 11.36 \\
\hline Tmem154 & ILC & 7.39 & 7.08 & 7.11 & 7.14 & 7.37 & 7.48 & 7.48 & 7.22 & 7.90 & 7.39 & 6.95 & 6.99 & 6.99 \\
\hline Ckb & ILC & 7.46 & 7.34 & 7.61 & 7.69 & 7.36 & 7.56 & 7.61 & 7.68 & 8.37 & 8.28 & 7.62 & 8.12 & 8.29 \\
\hline Cdon & ILC & 8.50 & 8.35 & 8.31 & 8.21 & 8.34 & 8.59 & 8.57 & 8.59 & 9.15 & 8.86 & 7.49 & 8.00 & 7.59 \\
\hline Gpr114 & ILC & 12.51 & 12.21 & 12.56 & 12.14 & 12.24 & 12.85 & 13.03 & 12.85 & 13.82 & 13.67 & 12.11 & 12.58 & 12.34 \\
\hline Slc27a6 & ILC & 9.37 & 9.57 & 9.58 & 9.88 & 10.05 & 9.98 & 10.10 & 10.25 & 11.35 & 11.03 & 9.77 & 10.41 & 9.54 \\
\hline Tmem176b & ILC & 11.47 & 11.36 & 11.39 & 11.93 & 11.72 & 12.35 & 12.53 & 12.42 & 13.35 & 13.07 & 10.54 & 11.65 & 11.05 \\
\hline Tmem176a & ILC & 10.03 & 10.00 & 9.88 & 10.39 & 10.23 & 10.75 & 11.09 & 10.80 & 12.02 & 11.58 & 9.00 & 10.14 & 9.67 \\
\hline $112 \mathrm{ra}$ & ILC & 10.11 & 9.89 & 10.78 & 9.58 & 10.27 & 10.84 & 10.75 & 10.68 & 12.42 & 11.91 & 10.54 & 11.28 & 10.74 \\
\hline Gpr97 & ILC & 10.48 & 9.81 & 10.60 & 10.43 & 10.12 & 10.94 & 11.11 & 11.17 & 12.65 & 12.57 & 10.98 & 11.31 & 11.38 \\
\hline Tcrg-V1 & ILC & 8.80 & 8.52 & 8.61 & 8.09 & 8.25 & 9.17 & 9.26 & 9.01 & 10.88 & 10.48 & 8.71 & 8.55 & 8.88 \\
\hline $117 r$ & ILC & 12.27 & 12.14 & 11.59 & 11.19 & 11.86 & 12.26 & 12.33 & 11.68 & 14.10 & 13.47 & 10.22 & 11.95 & 10.94 \\
\hline Cxcr6 & ILC & 11.94 & 11.70 & 11.82 & 11.94 & 11.78 & 12.51 & 12.56 & 12.70 & 14.85 & 14.50 & 11.39 & 12.35 & 11.78 \\
\hline
\end{tabular}


Z-score Table

PMA skin

Papilloma skin

Tumor skin

Papilloma

Tumor

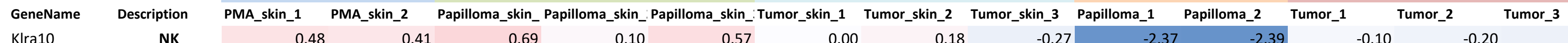

$\begin{array}{lllllll}0.48 & 0.41 & 0.69 & 0.10 & 0.57 & 0.00 & 0.18 \\ 0.91 & 1.14 & 0.63 & 0.25 & 0.87 & 0.09 & 0.00\end{array}$

$-2.39-0.10$

10 $-0.20-0.23$

KIra9

KIrg1

Irf8

Car5b

Zeb2

Eomes

Khdc1a

Cmklr1

Cym

A430084P05Ril

Itgam

Serpinb9b

KIra1

Socs2

St6galnac3

Atp8a2

Podnl1

Tmem154

Ckb

Cdon

Gpr114

Slc27a6

Tmem176b

Tmem176a

IIra

Gpr97

Tcrg-V1

$117 r$

Cxcr6

\begin{tabular}{|c|c|c|c|c|c|}
\hline 0.91 & 1.14 & 0.63 & 0.25 & 0.87 & 0.09 \\
\hline 0.37 & 0.39 & 0.44 & 0.01 & 0.31 & 0.03 \\
\hline-0.33 & 0.90 & 0.44 & 0.84 & 0.00 & 0.15 \\
\hline 1.16 & 0.82 & 1.00 & -0.63 & 0.85 & 0.23 \\
\hline 0.86 & 1.02 & 0.15 & 1.07 & 1.02 & 0.12 \\
\hline 1.06 & 1.16 & 1.45 & -0.22 & -0.07 & -0.15 \\
\hline 0.00 & 1.31 & 0.48 & -0.35 & -1.21 & 0.00 \\
\hline 1.63 & 1.03 & 0.80 & 0.57 & 0.00 & -0.70 \\
\hline 1.13 & 1.21 & 0.00 & 0.07 & 0.51 & 0.43 \\
\hline 0.46 & 1.45 & 0.87 & 0.60 & 2.09 & -0.22 \\
\hline 1.06 & 1.05 & 0.99 & 0.45 & -0.40 & 0.00 \\
\hline 1.75 & -0.37 & 0.00 & 0.39 & -0.29 & 1.06 \\
\hline 1.56 & 1.26 & 1.74 & 0.26 & 0.85 & 0.00 \\
\hline 0.00 & -0.56 & 0.24 & 0.21 & 0.22 & 0.56 \\
\hline 0.00 & -0.59 & -1.74 & -0.26 & -1.45 & 0.96 \\
\hline-1.00 & 1.03 & -0.45 & 0.66 & 0.00 & 1.25 \\
\hline-1.59 & -2.34 & -1.03 & -0.99 & -1.23 & 0.00 \\
\hline 0.63 & -0.53 & -0.41 & -0.31 & 0.56 & 0.95 \\
\hline-0.43 & -0.78 & -0.02 & 0.21 & -0.70 & -0.15 \\
\hline 0.32 & 0.00 & -0.08 & -0.31 & -0.02 & 0.52 \\
\hline-0.10 & -0.64 & 0.00 & -0.76 & -0.59 & 0.53 \\
\hline-1.04 & -0.69 & -0.69 & -0.17 & 0.11 & 0.00 \\
\hline-0.32 & -0.46 & -0.41 & 0.26 & 0.00 & 0.78 \\
\hline-0.24 & -0.28 & -0.42 & 0.21 & 0.00 & 0.65 \\
\hline-0.81 & -1.09 & 0.05 & -1.49 & -0.60 & 0.13 \\
\hline-0.59 & -1.40 & -0.45 & -0.65 & -1.03 & -0.04 \\
\hline 0.00 & -0.35 & -0.24 & -0.88 & -0.68 & 0.46 \\
\hline 0.32 & 0.19 & -0.36 & -0.76 & -0.09 & 0.31 \\
\hline 0.00 & -0.22 & -0.12 & 0.00 & -0.15 & 0.54 \\
\hline
\end{tabular}

$0.00 \quad-0.39$

0.00
-0.37

$-2.40$

$-1.83$

$-0.40$

$\begin{array}{llllll}0.00 & -2.38 & -2.04 & 0.17 & -0.96 & 0.23 \\ -0.23 & -0.67 & -2.62 & -0.33 & 0.60 & -0.09\end{array}$

-0.96
$0.60-0.09$

$\begin{array}{rrrrrrr}0.00 & -0.96 & -1.08 & -1.79 & -1.16 & -1.19 & -0.66 \\ -1.03 & 0.00 & -1.91 & -1.57 & 0.39 & 0.25 & 0.07\end{array}$

\begin{tabular}{lllllll}
0.61 & -0.85 & -2.35 & 0.37 & 0.57 & 1.03 \\
\hline
\end{tabular}

\begin{tabular}{rrrrrrr}
0.15 & -0.32 & -1.27 & -1.74 & -1.05 & -1.11 & 0.05 \\
\hline .74 & -0.67 & -1.03 & -0.90 & -1.75 & -1.60 & -0.98
\end{tabular}

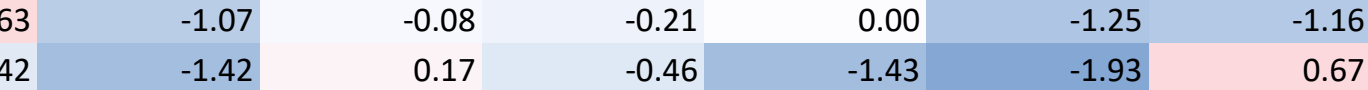

\begin{tabular}{rrrrrrr}
-39 & -0.79 & 1.66 & -0.96 & -0.80 & 0.04 & 0.82 \\
\hline .09 & -0.58 & -0.09 & 0.85 & -0.77 & -1.34 & -1.10
\end{tabular}

$\begin{array}{rrrrrrr}0.86 & -1.65 & -2.16 & -1.60 & -0.26 & -1.36 \\ 0.60 & 0.81 & 0.85 & -0.65 & -0.18 & 1.43 & 1.17\end{array}$

\begin{tabular}{rrrrrrr}
0.81 & 0.85 & -0.65 & -0.18 & 1.43 & 1.17 \\
\hline 0.84 & 1.41 & -0.12 & 2.06 & -0.46 & -0.79 & -0.95
\end{tabular}

\begin{tabular}{rrrrrrr}
0.98 & 0.42 & 0.20 & 0.01 & 0.33 & 1.10 & 0.68 \\
\hline 0.01 & 0.00 & 2.52 & 0.64 & -1.02 & -0.86 & -0.86
\end{tabular}

\begin{tabular}{rrrrrrr}
.01 & 0.18 & 2.07 & 1.81 & 0.00 & 1.38 & 1.84 \\
\hline .48 & 0.53 & 1.73 & 1.11 & -1.87 & -0.75 & -1.64 \\
\hline
\end{tabular}

$\begin{array}{lllllll}0.48 & 0.51 & 2.27 & 2.00 & -0.83 & 0.02 & -0.40 \\ 0.20 & 0.46 & 2.35 & 1.79 & -0.36 & 0.73 & -0.76\end{array}$

$\begin{array}{lllllll}0.06 & 2.03 & 1.67 & -1.47 & -0.09 & -0.84 \\ 0.06 & 0.71 & 2.21 & 1.67 & -1.51 & -0.11 & -0.68\end{array}$

\begin{tabular}{lllllll}
0.02 & -0.08 & 2.17 & 1.51 & -0.26 & 0.70 & 0.00 \\
\hline 0.16 & 0.23 & 2.00 & 1.90 & 0.00 & 0.40 & 0.48
\end{tabular}

\begin{tabular}{rrrrrrr}
0.57 & 0.26 & 2.56 & 2.06 & -0.11 & -0.31 & 0.10 \\
\hline .38 & -0.27 & 2.14 & 1.52 & -1.72 & 0.00 & -1.00
\end{tabular}

ILC

0.00

$-0.12$

0.58

2.74

$\begin{array}{lll}2.41 & -0.52 & 0.38\end{array}$

$-0.16$ 


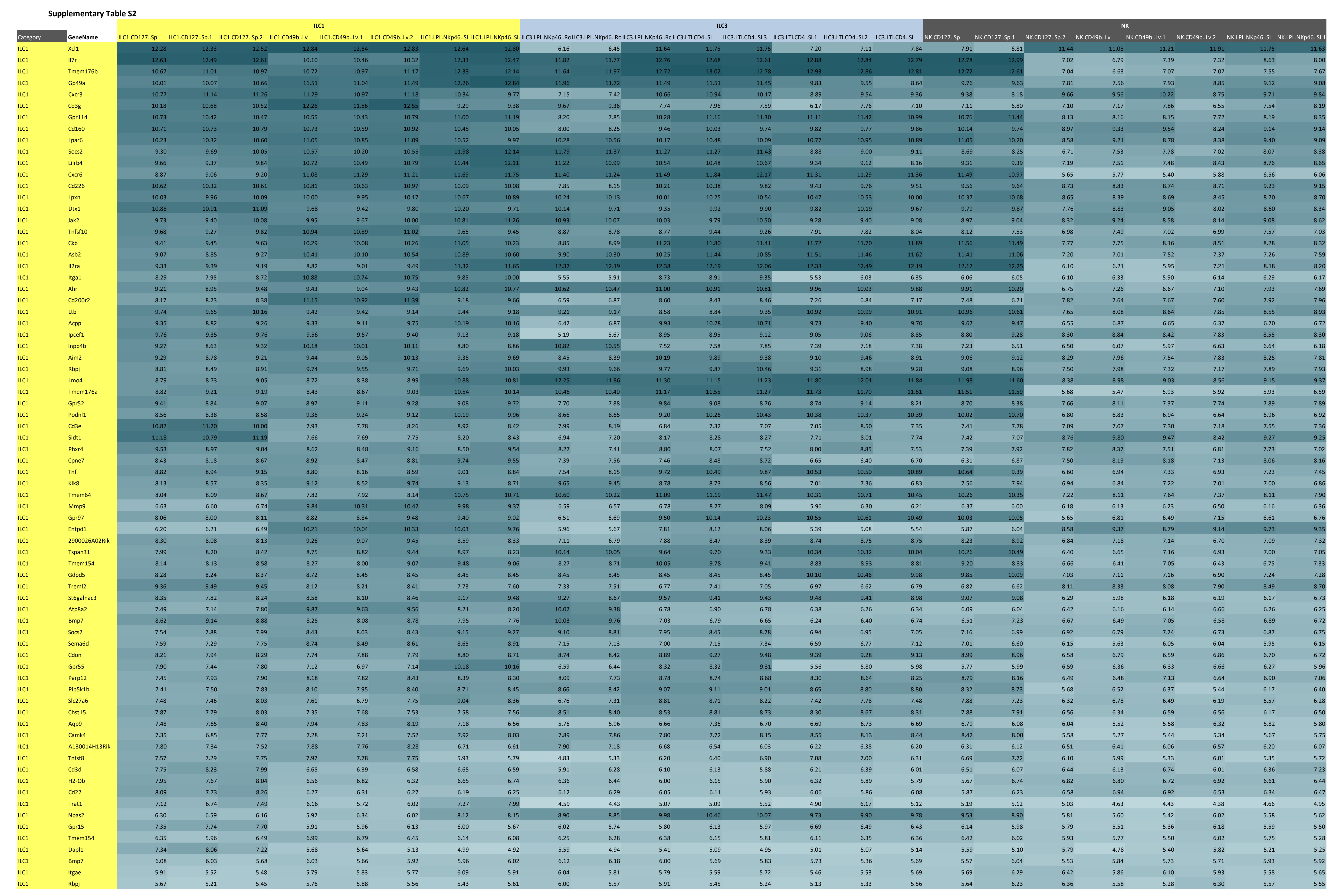




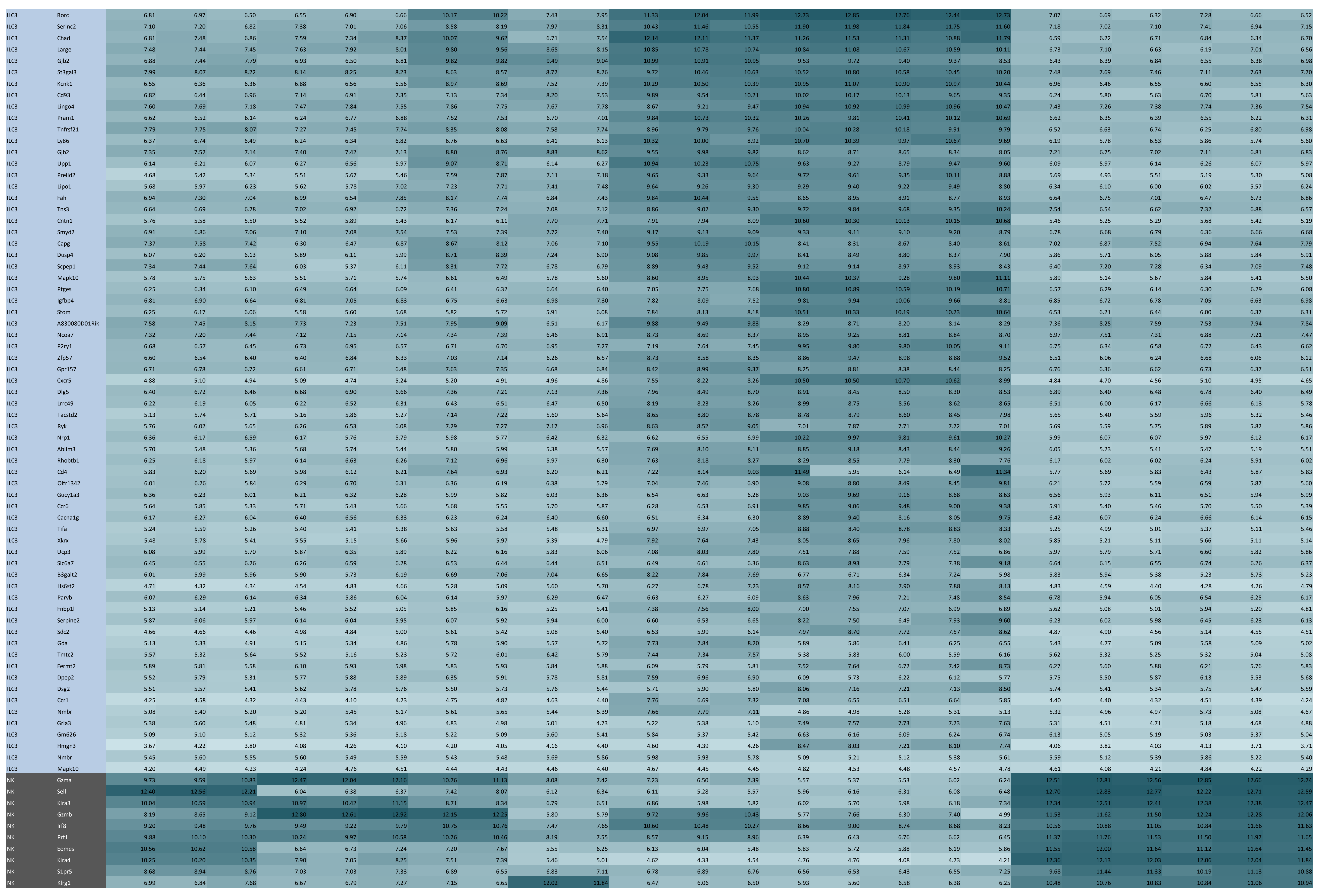




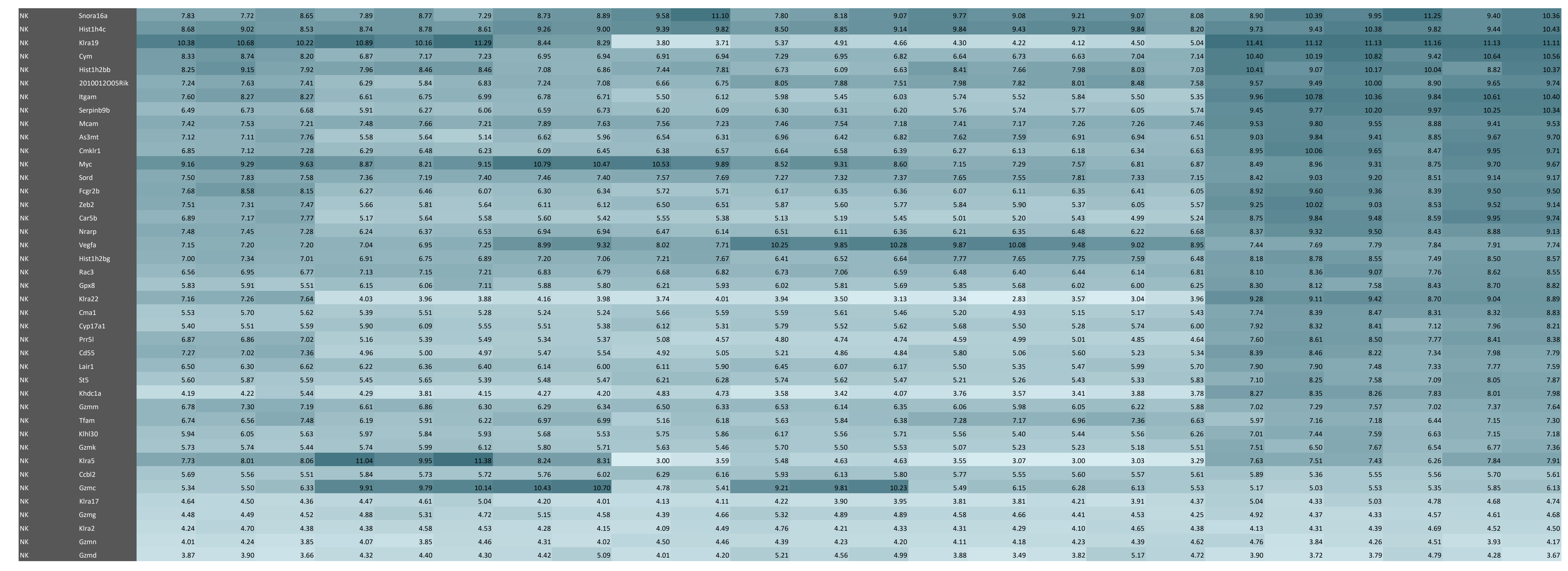




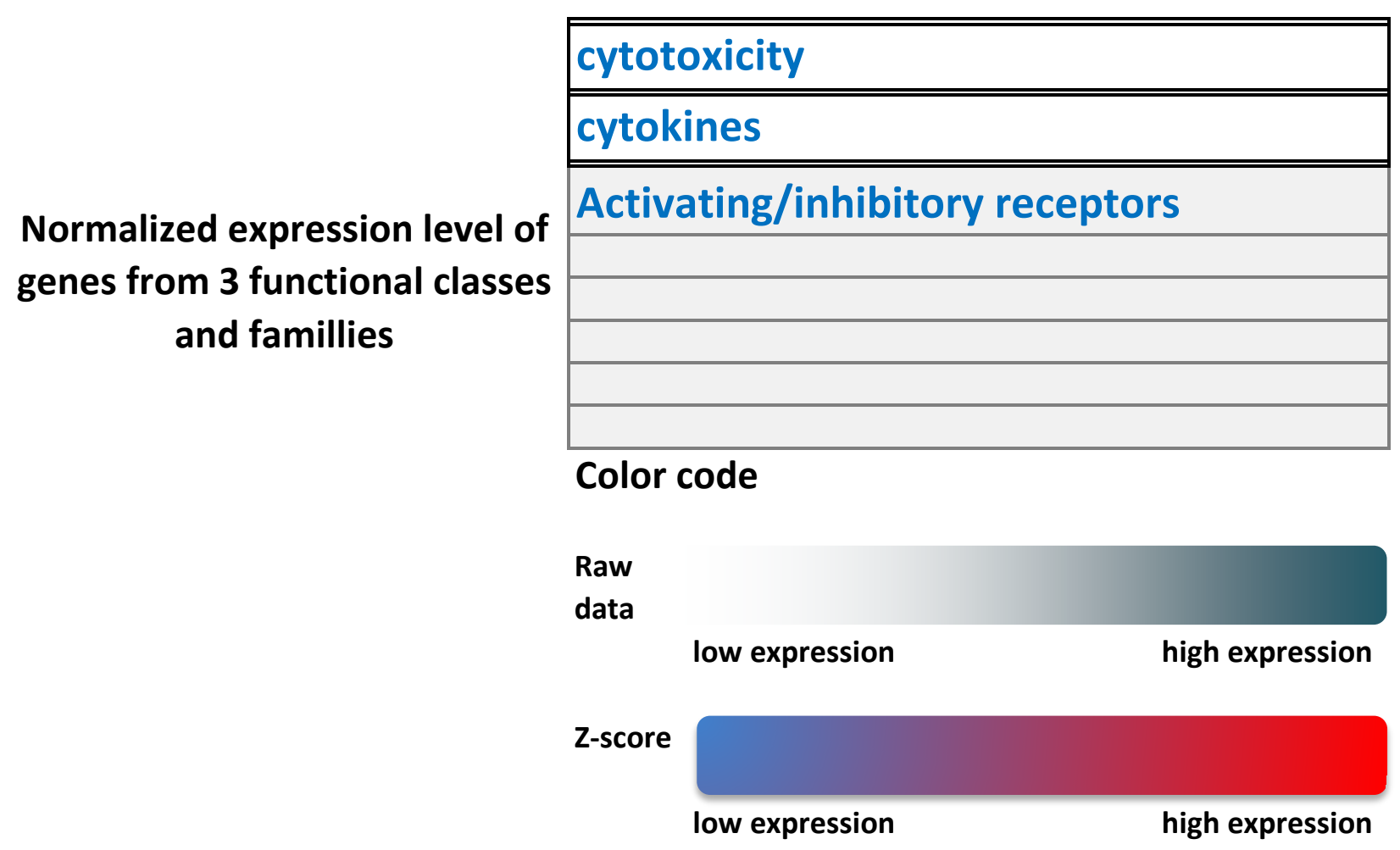


Supplementary Table S3: cytotoxicity genes

\begin{tabular}{|c|c|c|c|c|c|c|c|c|c|c|c|c|c|}
\hline \multirow{2}{*}{$\begin{array}{c}\text { Raw data } \\
\text { table } \\
\text { GeneName }\end{array}$} & \multicolumn{2}{|c|}{ PMA skin } & \multicolumn{3}{|c|}{ Papilloma skin } & \multicolumn{3}{|c|}{ Tumor skin } & \multicolumn{2}{|c|}{ Papilloma } & \multicolumn{3}{|c|}{ Tumor } \\
\hline & PMA_skin_1 & PMA_skin_2 & Papilloma_skin_ & Papilloma_skin_ & Papilloma_skin_ & Tumor_skin_1 & Tumor_skin_2 & Tumor_skin_3 & Papilloma_1 & Papilloma_2 & Tumor_1 & Tumor_2 & Tumor_3 \\
\hline Tnfsf10 & 11.59 & 11.22 & 11.24 & 10.99 & 11.44 & 11.61 & 11.75 & 11.56 & 12.79 & 12.54 & 10.82 & 11.27 & 10.76 \\
\hline Gzma & 18.04 & 18.07 & 18.06 & 18.19 & 18.02 & 18.04 & 18.08 & 18.23 & 17.10 & 17.05 & 17.88 & 17.81 & 17.72 \\
\hline Gzmb & 15.46 & 15.59 & 15.69 & 15.36 & 15.37 & 15.48 & 15.23 & 15.61 & 14.01 & 14.32 & 15.59 & 15.27 & 15.28 \\
\hline Prf1 & 15.08 & 15.26 & 15.13 & 15.13 & 15.06 & 14.82 & 15.05 & 15.04 & 14.10 & 14.09 & 15.17 & 14.91 & 15.12 \\
\hline Gzmm & 10.74 & 10.27 & 10.56 & 10.62 & 11.26 & 10.78 & 10.94 & 10.47 & 9.36 & 9.48 & 10.82 & 10.97 & 10.62 \\
\hline Fasl & 13.94 & 13.93 & 14.22 & 14.04 & 14.17 & 13.92 & 13.70 & 14.10 & 13.08 & 13.19 & 13.51 & 13.39 & 13.08 \\
\hline Gzmc & 14.89 & 15.71 & 15.11 & 15.40 & 16.36 & 15.51 & 15.88 & 15.53 & 16.39 & 16.58 & 16.40 & 16.96 & 15.58 \\
\hline Fas & 9.14 & 8.99 & 9.04 & 8.60 & 9.11 & 9.44 & 9.39 & 8.95 & 8.97 & 8.03 & 9.10 & 9.67 & 9.38 \\
\hline Gzme & 5.83 & 5.67 & 6.07 & 6.32 & 6.94 & 9.10 & 7.83 & 8.68 & 5.53 & 5.60 & 14.26 & 14.46 & 13.10 \\
\hline Gzmf & 5.17 & 4.83 & 5.57 & 5.22 & 6.47 & 7.06 & 6.98 & 6.88 & 4.70 & 5.14 & 11.73 & 12.10 & 10.69 \\
\hline Gzmd & 4.94 & 5.24 & 5.06 & 5.48 & 6.65 & 6.68 & 5.88 & 6.47 & 5.29 & 6.17 & 11.22 & 11.85 & 9.84 \\
\hline Gzmg & 6.02 & 5.60 & 5.43 & 5.49 & 5.89 & 6.26 & 5.70 & 5.95 & 5.74 & 5.72 & 10.63 & 11.07 & 10.23 \\
\hline
\end{tabular}

\begin{tabular}{|c|c|c|c|c|c|c|c|c|c|c|c|c|c|}
\hline \multirow{2}{*}{$\begin{array}{l}\text { Z-Score table } \\
\text { GeneName }\end{array}$} & \multicolumn{2}{|c|}{ PMA skin } & \multicolumn{3}{|c|}{ Papilloma skin } & \multicolumn{3}{|c|}{ Tumor skin } & \multicolumn{2}{|c|}{ Papilloma } & \multicolumn{3}{|c|}{ Tumor } \\
\hline & PMA_skin_1 & PMA_skin_2 & Papilloma_skin_ & Papilloma_skin_ & Papilloma_skin_ & Tumor_skin_1 & Tumor_skin_2 & Tumor_skin_3 & Papilloma_1 & Papilloma_2 & Tumor_1 & Tumor_2 & Tumor_3 \\
\hline Tnfsf10 & 0.25 & -0.36 & -0.33 & -0.75 & 0.00 & 0.29 & 0.52 & 0.20 & 2.26 & 1.84 & -1.03 & -0.28 & -1.12 \\
\hline Gzma & 0.00 & 0.10 & 0.07 & 0.41 & -0.04 & 0.00 & 0.12 & 0.51 & -2.47 & -2.60 & -0.43 & -0.59 & -0.83 \\
\hline Gzmb & 0.19 & 0.45 & 0.63 & -0.02 & 0.00 & 0.23 & -0.27 & 0.47 & -2.68 & -2.07 & 0.43 & -0.19 & -0.17 \\
\hline Prf1 & 0.05 & 0.53 & 0.19 & 0.18 & 0.00 & -0.62 & -0.01 & -0.04 & -2.50 & -2.53 & 0.30 & -0.38 & 0.17 \\
\hline Gzmm & 0.22 & -0.64 & -0.11 & 0.00 & 1.16 & 0.28 & 0.59 & -0.28 & -2.29 & -2.07 & 0.36 & 0.63 & 0.00 \\
\hline Fasl & 0.03 & 0.01 & 0.72 & 0.29 & 0.58 & 0.00 & -0.54 & 0.43 & -2.02 & -1.75 & -0.99 & -1.29 & -2.02 \\
\hline Gzmc & -1.32 & 0.00 & -0.96 & -0.49 & 1.06 & -0.31 & 0.29 & -0.29 & 1.11 & 1.42 & 1.12 & 2.03 & -0.20 \\
\hline Fas & 0.09 & -0.27 & -0.15 & -1.21 & 0.04 & 0.84 & 0.71 & -0.36 & -0.32 & -2.59 & 0.00 & 1.39 & 0.67 \\
\hline Gzme & -0.33 & -0.38 & -0.26 & -0.18 & 0.00 & 0.64 & 0.26 & 0.52 & -0.42 & -0.40 & 2.17 & 2.23 & 1.83 \\
\hline Gzmf & -0.49 & -0.62 & -0.34 & -0.47 & 0.00 & 0.23 & 0.20 & 0.16 & -0.67 & -0.50 & 1.99 & 2.13 & 1.60 \\
\hline Gzmd & -0.52 & -0.39 & -0.47 & -0.29 & 0.20 & 0.21 & -0.12 & 0.13 & -0.37 & 0.00 & 2.12 & 2.38 & 1.54 \\
\hline Gzmg & 0.06 & -0.13 & -0.21 & -0.18 & 0.00 & 0.18 & -0.09 & 0.03 & -0.07 & -0.08 & 2.21 & 2.41 & 2.02 \\
\hline
\end{tabular}


Supplementary Table S3: cytokine genes

\begin{tabular}{|c|c|c|c|c|c|c|c|c|c|c|c|c|c|}
\hline \multirow{2}{*}{$\begin{array}{c}\text { Raw data } \\
\text { table } \\
\text { GeneName }\end{array}$} & \multicolumn{2}{|c|}{ PMA skin } & \multicolumn{3}{|c|}{ Papilloma skin } & \multicolumn{3}{|c|}{ Tumor skin } & \multicolumn{2}{|c|}{ Papilloma } & \multicolumn{3}{|c|}{ Tumor } \\
\hline & PMA_skin_1 & PMA_skin_2 & Papilloma_skin_ & Papilloma_skin_ & Papilloma_skin_ & -Tumor_skin_1 & Tumor_skin_2 & Tumor_skin_3 & Papilloma_1 & Papilloma_2 & Tumor_1 & Tumor_2 & Tumor_3 \\
\hline Csf1 & 6.39 & 6.33 & 5.50 & 6.10 & 5.20 & 6.37 & 6.06 & 5.93 & 6.82 & 5.86 & 6.72 & 7.20 & 8.36 \\
\hline Ifna13 & 6.00 & 6.21 & 6.16 & 6.03 & 5.95 & 6.16 & 6.11 & 6.12 & 5.93 & 6.09 & 6.25 & 6.10 & 6.26 \\
\hline TxIna & 9.81 & 9.83 & 9.71 & 9.71 & 9.50 & 9.72 & 9.68 & 9.80 & 9.66 & 9.97 & 9.86 & 9.64 & 10.00 \\
\hline Csf2 & 10.34 & 10.62 & 11.35 & 10.56 & 11.54 & 11.50 & 10.73 & 10.99 & 13.10 & 12.95 & 11.62 & 12.51 & 11.46 \\
\hline Cxcl1 & 6.44 & 7.13 & 6.27 & 7.26 & 7.41 & 7.88 & 6.35 & 6.96 & 8.71 & 8.13 & 6.84 & 9.17 & 7.43 \\
\hline $\mathrm{Cxcl} 2$ & 7.80 & 8.50 & 6.61 & 6.57 & 6.24 & 9.74 & 7.56 & 7.47 & 12.71 & 11.37 & 8.80 & 11.38 & 11.33 \\
\hline$\| 1 b$ & 10.15 & 10.44 & 5.49 & 5.95 & 6.29 & 11.48 & 7.26 & 8.10 & 15.18 & 13.50 & 9.76 & 12.55 & 11.95 \\
\hline$\| 13$ & 6.05 & 6.16 & 5.31 & 5.60 & 4.73 & 6.65 & 5.90 & 5.19 & 9.22 & 8.33 & 6.54 & 6.53 & 8.52 \\
\hline$\| 17 a$ & 5.73 & 6.68 & 6.03 & 5.82 & 5.76 & 5.87 & 5.85 & 5.00 & 10.01 & 9.26 & 6.57 & 6.80 & 7.87 \\
\hline$\| 17 f$ & 5.64 & 6.01 & 6.06 & 5.98 & 5.65 & 6.20 & 6.20 & 5.94 & 8.04 & 7.42 & 6.22 & 6.16 & 6.94 \\
\hline Tnf & 12.11 & 12.04 & 12.10 & 12.44 & 12.04 & 12.31 & 12.36 & 11.80 & 13.64 & 13.58 & 12.15 & 12.46 & 13.02 \\
\hline I|22 & 6.35 & 5.95 & 6.18 & 6.04 & 6.16 & 6.24 & 6.34 & 5.97 & 6.63 & 6.77 & 6.50 & 6.38 & 6.64 \\
\hline 114 & 5.61 & 6.23 & 5.85 & 6.02 & 5.81 & 5.99 & 6.46 & 5.95 & 7.97 & 7.69 & 5.65 & 5.52 & 5.97 \\
\hline 116 & 5.71 & 7.48 & 6.91 & 5.84 & 6.99 & 6.64 & 6.99 & 7.09 & 10.14 & 9.46 & 6.09 & 7.83 & 5.97 \\
\hline Ifnab & 6.14 & 6.29 & 6.22 & 6.40 & 6.14 & 6.23 & 6.32 & 6.37 & 6.42 & 6.78 & 6.49 & 6.27 & 6.43 \\
\hline Ifna5 & 7.08 & 6.78 & 6.87 & 6.85 & 6.94 & 6.71 & 6.95 & 6.61 & 7.44 & 8.31 & 7.33 & 6.94 & 7.11 \\
\hline $1128 b$ & 6.62 & 6.55 & 6.79 & 6.77 & 6.85 & 6.57 & 6.78 & 6.55 & 7.09 & 7.76 & 7.00 & 6.61 & 6.91 \\
\hline$\| 34$ & 6.70 & 7.09 & 6.61 & 7.19 & 6.78 & 6.59 & 6.44 & 6.72 & 7.08 & 7.53 & 6.95 & 7.28 & 7.07 \\
\hline II18 & 7.70 & 7.32 & 7.91 & 7.69 & 8.09 & 7.78 & 8.04 & 8.03 & 8.33 & 8.42 & 8.48 & 8.36 & 7.99 \\
\hline Ifnk & 6.42 & 6.31 & 6.96 & 6.60 & 6.35 & 7.14 & 6.90 & 7.53 & 6.97 & 6.52 & 6.96 & 6.98 & 6.82 \\
\hline Ifna2 & 6.00 & 6.03 & 6.23 & 6.15 & 6.00 & 6.08 & 6.30 & 6.15 & 5.96 & 5.94 & 6.13 & 5.95 & 6.23 \\
\hline$\| 16$ & 11.82 & 11.87 & 11.86 & 11.86 & 11.73 & 12.03 & 12.30 & 12.21 & 11.81 & 11.94 & 11.83 & 11.80 & 11.91 \\
\hline Ifna14 & 7.29 & 7.21 & 7.49 & 7.10 & 7.10 & 7.24 & 7.13 & 7.14 & 7.28 & 6.88 & 7.28 & 7.18 & 7.43 \\
\hline$\| 11$ & 6.39 & 6.44 & 6.68 & 6.27 & 6.12 & 6.21 & 6.45 & 6.31 & 6.32 & 5.48 & 6.34 & 6.66 & 6.68 \\
\hline II15 & 6.77 & 6.86 & 6.26 & 6.39 & 6.56 & 6.51 & 6.56 & 6.31 & 6.61 & 5.79 & 6.56 & 6.68 & 6.61 \\
\hline 117 & 5.81 & 5.78 & 6.30 & 7.67 & 6.97 & 6.21 & 5.73 & 6.03 & 5.66 & 5.35 & 5.98 & 5.87 & 5.84 \\
\hline TxIng & 7.30 & 7.44 & 7.41 & 7.38 & 7.45 & 7.35 & 7.39 & 7.29 & 6.54 & 6.66 & 7.30 & 7.38 & 7.29 \\
\hline Ifng & 16.34 & 16.50 & 16.65 & 16.66 & 16.65 & 16.27 & 16.23 & 16.37 & 16.30 & 16.38 & 15.57 & 15.69 & 15.42 \\
\hline 112 & 10.94 & 10.94 & 10.38 & 9.52 & 10.68 & 10.71 & 10.76 & 10.33 & 11.21 & 10.51 & 7.31 & 8.94 & 7.68 \\
\hline Ifna1 & 7.17 & 6.94 & 7.22 & 6.88 & 7.25 & 6.90 & 6.95 & 6.69 & 7.24 & 7.03 & 6.92 & 6.95 & 6.92 \\
\hline$\| 17 d$ & 7.58 & 7.80 & 7.69 & 7.51 & 8.06 & 7.48 & 7.31 & 7.09 & 7.61 & 7.53 & 7.33 & 7.27 & 7.29 \\
\hline 1|27 & 8.48 & 8.41 & 8.71 & 8.45 & 8.69 & 8.30 & 8.45 & 8.14 & 8.37 & 8.22 & 8.38 & 8.27 & 8.49 \\
\hline II3 & 6.56 & 6.45 & 6.73 & 6.32 & 6.44 & 6.52 & 6.37 & 6.27 & 6.62 & 6.15 & 6.17 & 6.30 & 6.36 \\
\hline
\end{tabular}




\begin{tabular}{|c|c|c|c|c|c|c|c|c|c|c|c|c|c|}
\hline \multirow{2}{*}{$\begin{array}{l}\text { Z-Score table } \\
\text { GeneName }\end{array}$} & \multicolumn{2}{|c|}{ PMA skin } & \multicolumn{3}{|c|}{ Papilloma skin } & \multicolumn{3}{|c|}{ Tumor skin } & \multicolumn{2}{|c|}{ Papilloma } & \multicolumn{3}{|c|}{ Tumor } \\
\hline & PMA_skin_1 & PMA_skin_2 & Papilloma_skin_ & Papilloma_skin_ & Papilloma_skin_ & Tumor_skin_1 & Tumor_skin_2 & Tumor_skin_3 & Papilloma_1 & Papilloma_2 & Tumor_1 & Tumor_2 & Tumor_3 \\
\hline Csf1 & 0.08 & 0.00 & -1.03 & -0.29 & -1.40 & 0.05 & -0.34 & -0.50 & 0.61 & -0.59 & 0.49 & 1.09 & 2.53 \\
\hline Ifna13 & -1.07 & 0.99 & 0.45 & -0.76 & -1.50 & 0.45 & 0.00 & 0.06 & -1.72 & -0.23 & 1.32 & -0.13 & 1.38 \\
\hline TxIna & 0.60 & 0.76 & -0.09 & -0.10 & -1.64 & 0.00 & -0.33 & 0.58 & -0.49 & 1.78 & 1.00 & -0.63 & 2.01 \\
\hline Csf2 & -1.26 & -0.95 & -0.12 & -1.01 & 0.09 & 0.04 & -0.82 & -0.53 & 1.83 & 1.66 & 0.18 & 1.18 & 0.00 \\
\hline Cxcl1 & -0.92 & -0.15 & -1.12 & 0.00 & 0.17 & 0.69 & -1.03 & -0.34 & 1.62 & 0.98 & -0.47 & 2.14 & 0.19 \\
\hline Cxcl2 & -0.33 & 0.00 & -0.87 & -0.89 & -1.04 & 0.57 & -0.44 & -0.48 & 1.94 & 1.32 & 0.13 & 1.33 & 1.30 \\
\hline$\| 1 b$ & 0.00 & 0.09 & -1.52 & -1.37 & -1.26 & 0.43 & -0.94 & -0.67 & 1.64 & 1.09 & -0.13 & 0.78 & 0.58 \\
\hline$\| 13$ & -0.08 & 0.00 & -0.62 & -0.41 & -1.05 & 0.36 & -0.19 & -0.71 & 2.22 & 1.58 & 0.27 & 0.27 & 1.72 \\
\hline$\| 17 \mathrm{a}$ & -0.20 & 0.44 & 0.00 & -0.14 & -0.18 & -0.11 & -0.12 & -0.70 & 2.69 & 2.18 & 0.36 & 0.52 & 1.25 \\
\hline$\| 17 f$ & -0.75 & -0.21 & -0.14 & -0.27 & -0.73 & 0.05 & 0.05 & -0.32 & 2.67 & 1.79 & 0.08 & 0.00 & 1.10 \\
\hline Tnf & -0.35 & -0.45 & -0.36 & 0.22 & -0.47 & 0.00 & 0.09 & -0.87 & 2.27 & 2.17 & -0.27 & 0.26 & 1.21 \\
\hline II22 & 0.04 & -1.47 & -0.60 & -1.14 & -0.68 & -0.37 & 0.00 & -1.42 & 1.10 & 1.64 & 0.62 & 0.15 & 1.14 \\
\hline$\| 4$ & -0.47 & 0.33 & -0.16 & 0.06 & -0.21 & 0.03 & 0.64 & -0.03 & 2.62 & 2.25 & -0.43 & -0.59 & 0.00 \\
\hline 116 & -0.95 & 0.37 & -0.05 & -0.85 & 0.00 & -0.26 & 0.01 & 0.08 & 2.35 & 1.85 & -0.67 & 0.63 & -0.76 \\
\hline Ifnab & -1.01 & -0.15 & -0.54 & 0.48 & -1.06 & -0.49 & 0.00 & 0.34 & 0.63 & 2.73 & 0.99 & -0.30 & 0.66 \\
\hline Ifna5 & 0.32 & -0.37 & -0.15 & -0.21 & -0.01 & -0.54 & 0.01 & -0.75 & 1.14 & 3.12 & 0.87 & 0.00 & 0.38 \\
\hline II28b & -0.47 & -0.68 & 0.05 & -0.03 & 0.22 & -0.62 & 0.00 & -0.69 & 0.97 & 3.00 & 0.69 & -0.51 & 0.39 \\
\hline ॥134 & -0.79 & 0.45 & -1.07 & 0.77 & -0.54 & -1.13 & -1.62 & -0.72 & 0.42 & 1.82 & 0.00 & 1.05 & 0.39 \\
\hline II18 & -0.99 & -2.10 & -0.34 & -1.00 & 0.18 & -0.73 & 0.03 & 0.00 & 0.89 & 1.16 & 1.35 & 1.00 & -0.12 \\
\hline Ifnk & -1.36 & -1.68 & 0.19 & -0.85 & -1.57 & 0.69 & 0.00 & 1.80 & 0.22 & -1.06 & 0.19 & 0.25 & -0.23 \\
\hline Ifna2 & -0.63 & -0.41 & 1.26 & 0.64 & -0.65 & 0.00 & 1.87 & 0.64 & -0.98 & -1.14 & 0.41 & -1.06 & 1.30 \\
\hline II16 & -0.26 & 0.05 & 0.00 & -0.01 & -0.83 & 0.98 & 2.65 & 2.06 & -0.33 & 0.45 & -0.18 & -0.39 & 0.26 \\
\hline Ifna14 & 0.48 & 0.00 & 1.79 & -0.73 & -0.74 & 0.14 & -0.51 & -0.45 & 0.45 & -2.15 & 0.45 & -0.19 & 1.39 \\
\hline$\| 11$ & 0.18 & 0.32 & 1.09 & -0.21 & -0.70 & -0.41 & 0.37 & -0.07 & -0.05 & -2.75 & 0.00 & 1.03 & 1.10 \\
\hline II15 & 0.76 & 1.11 & -1.11 & -0.63 & -0.03 & -0.18 & 0.00 & -0.92 & 0.18 & -2.85 & 0.01 & 0.44 & 0.19 \\
\hline 117 & -0.11 & -0.16 & 0.70 & 2.93 & 1.79 & 0.54 & -0.23 & 0.25 & -0.36 & -0.86 & 0.18 & 0.00 & -0.05 \\
\hline TxIng & -0.17 & 0.34 & 0.21 & 0.13 & 0.36 & 0.00 & 0.16 & -0.18 & -2.75 & -2.34 & -0.15 & 0.13 & -0.20 \\
\hline Ifng & 0.00 & 0.38 & 0.75 & 0.78 & 0.76 & -0.16 & -0.26 & 0.06 & -0.09 & 0.09 & -1.87 & -1.57 & -2.22 \\
\hline II2 & 0.34 & 0.34 & -0.11 & -0.78 & 0.13 & 0.16 & 0.19 & -0.15 & 0.55 & 0.00 & -2.53 & -1.24 & -2.24 \\
\hline Ifna1 & 1.34 & -0.02 & 1.64 & -0.39 & 1.80 & -0.30 & 0.03 & -1.52 & 1.74 & 0.47 & -0.14 & 0.00 & -0.16 \\
\hline$\| 17 d$ & 0.28 & 1.15 & 0.71 & 0.00 & 2.15 & -0.09 & -0.75 & -1.64 & 0.42 & 0.07 & -0.67 & -0.92 & -0.85 \\
\hline ॥I27 & 0.48 & 0.00 & 1.83 & 0.28 & 1.73 & -0.66 & 0.27 & -1.61 & -0.19 & -1.11 & -0.17 & -0.85 & 0.53 \\
\hline$\| 3$ & 1.09 & 0.46 & 2.13 & -0.28 & 0.39 & 0.86 & 0.00 & -0.59 & 1.46 & -1.28 & -1.17 & -0.39 & -0.05 \\
\hline
\end{tabular}


Supplementary Table S3: inh/act receptors

\begin{tabular}{|c|c|c|c|c|c|c|c|c|c|c|c|c|c|}
\hline \multirow{2}{*}{$\begin{array}{c}\text { Raw data } \\
\text { table } \\
\text { GeneName }\end{array}$} & \multicolumn{2}{|c|}{ PMA skin } & \multicolumn{3}{|c|}{ Papilloma skin } & \multicolumn{3}{|c|}{ Tumor skin } & \multicolumn{2}{|c|}{ Papilloma } & \multicolumn{3}{|c|}{ Tumor } \\
\hline & PMA_skin_1 & PMA_skin_2 & Papilloma_skin_ & Papilloma_skin_ & Papilloma_skin_ & Tumor_skin_1 & Tumor_skin_2 & Tumor_skin_3 & Papilloma_1 & Papilloma_2 & Tumor_1 & Tumor_2 & Tumor_3 \\
\hline $\mathrm{Cd} 28$ & 13.39 & 13.25 & 13.45 & 13.39 & 13.42 & 13.62 & 13.16 & 13.52 & 13.27 & 13.29 & 12.13 & 12.44 & 12.14 \\
\hline Cd96 & 12.28 & 12.45 & 12.43 & 12.48 & 12.63 & 12.53 & 12.74 & 12.77 & 12.98 & 13.10 & 12.82 & 12.88 & 12.57 \\
\hline $\mathrm{Cd} 226$ & 10.71 & 10.33 & 10.48 & 10.60 & 10.74 & 10.79 & 10.38 & 10.31 & 10.48 & 10.12 & 8.92 & 9.74 & 9.29 \\
\hline Klrk1 & 10.76 & 10.95 & 10.60 & 10.59 & 10.70 & 10.69 & 10.72 & 10.81 & 10.43 & 10.41 & 10.22 & 10.14 & 9.98 \\
\hline Klrb1c & 8.49 & 8.16 & 8.50 & 7.98 & 8.46 & 8.14 & 8.30 & 7.96 & 6.98 & 6.40 & 7.57 & 7.85 & 7.34 \\
\hline Klrb1c & 15.07 & 14.84 & 15.23 & 14.95 & 15.19 & 15.04 & 15.36 & 15.29 & 14.22 & 14.07 & 14.51 & 14.68 & 14.43 \\
\hline KIrc2 & 8.38 & 8.10 & 7.98 & 8.28 & 7.91 & 8.40 & 7.78 & 7.59 & 7.42 & 6.64 & 7.13 & 6.85 & 7.66 \\
\hline $\mathrm{Cd} 244$ & 12.25 & 12.21 & 12.50 & 12.26 & 12.22 & 12.43 & 12.17 & 12.19 & 13.13 & 13.14 & 12.21 & 12.31 & 12.30 \\
\hline Klrg1 & 13.55 & 13.57 & 13.61 & 13.26 & 13.51 & 13.28 & 13.21 & 13.26 & 11.36 & 11.44 & 12.82 & 12.23 & 12.38 \\
\hline Ctla4 & 6.21 & 6.34 & 7.08 & 7.34 & 7.43 & 7.58 & 7.53 & 8.36 & 7.00 & 8.79 & 8.56 & 8.23 & 7.64 \\
\hline Pdcd1 & 6.78 & 6.76 & 6.49 & 6.49 & 7.10 & 7.64 & 7.40 & 7.72 & 9.10 & 9.40 & 8.94 & 10.07 & 8.95 \\
\hline $\mathrm{Cd} 274$ & 11.59 & 11.54 & 12.12 & 11.45 & 11.68 & 11.90 & 11.53 & 11.82 & 11.90 & 11.58 & 11.99 & 12.12 & 11.95 \\
\hline Tigit & 9.38 & 9.50 & 10.68 & 10.11 & 10.19 & 10.27 & 10.40 & 10.82 & 9.04 & 9.19 & 11.42 & 11.36 & 11.18 \\
\hline Havrc2 & 6.22 & 5.94 & 5.82 & 5.33 & 5.92 & 6.58 & 5.73 & 6.17 & 7.77 & 7.11 & 8.62 & 8.19 & 7.77 \\
\hline lag3 & 7.79 & 7.90 & 8.87 & 8.19 & 8.59 & 8.96 & 9.04 & 9.20 & 8.98 & 8.76 & 10.03 & 9.77 & 9.73 \\
\hline
\end{tabular}

\begin{tabular}{|c|c|c|c|c|c|c|c|c|c|c|c|c|c|}
\hline \multirow{2}{*}{$\begin{array}{l}\text { Z-Score table } \\
\text { GeneName }\end{array}$} & \multicolumn{2}{|c|}{ PMA skin } & \multicolumn{3}{|c|}{ Papilloma skin } & \multicolumn{3}{|c|}{ Tumor skin } & \multicolumn{2}{|c|}{ Papilloma } & \multicolumn{3}{|c|}{ Tumor } \\
\hline & PMA_skin_1 & PMA_skin_2 & Papilloma_skin_ & Papilloma_skin_P & Papilloma_skin_ & Tumor_skin_1 & Tumor_skin_2 & Tumor_skin_3 & Papilloma_1 & Papilloma_2 & Tumor_1 & Tumor_2 & Tumor_3 \\
\hline $\mathrm{Cd} 28$ & 0.19 & -0.09 & 0.31 & 0.18 & 0.23 & 0.62 & -0.25 & 0.44 & -0.04 & 0.00 & -2.24 & -1.65 & -2.23 \\
\hline Cd96 & -1.47 & -0.76 & -0.85 & -0.64 & 0.00 & -0.41 & 0.47 & 0.58 & 1.46 & 1.94 & 0.81 & 1.04 & -0.24 \\
\hline $\mathrm{Cd} 226$ & 0.57 & -0.10 & 0.16 & 0.37 & 0.63 & 0.70 & 0.00 & -0.12 & 0.17 & -0.46 & -2.56 & -1.12 & -1.90 \\
\hline Klrk1 & 0.56 & 1.20 & 0.00 & -0.04 & 0.35 & 0.32 & 0.40 & 0.72 & -0.60 & -0.68 & -1.35 & -1.62 & -2.16 \\
\hline Klrb1c & 0.80 & 0.30 & 0.83 & 0.00 & 0.77 & 0.25 & 0.51 & -0.02 & -1.57 & -2.49 & -0.64 & -0.20 & -1.01 \\
\hline Klrb1c & 0.28 & -0.26 & 0.65 & 0.00 & 0.56 & 0.22 & 0.96 & 0.81 & -1.75 & -2.09 & -1.05 & -0.64 & -1.23 \\
\hline KIrc2 & 1.07 & 0.56 & 0.36 & 0.88 & 0.23 & 1.09 & 0.00 & -0.34 & -0.63 & -2.02 & -1.15 & -1.64 & -0.22 \\
\hline $\mathrm{Cd} 244$ & -0.03 & -0.17 & 0.69 & 0.00 & -0.15 & 0.49 & -0.29 & -0.23 & 2.58 & 2.60 & -0.17 & 0.15 & 0.09 \\
\hline KIrg1 & 0.37 & 0.39 & 0.44 & 0.01 & 0.31 & 0.03 & -0.07 & 0.00 & -2.40 & -2.31 & -0.55 & -1.31 & -1.12 \\
\hline Ctla4 & -1.67 & -1.50 & -0.58 & -0.25 & -0.13 & 0.06 & 0.00 & 1.04 & -0.67 & 1.59 & 1.30 & 0.88 & 0.14 \\
\hline Pdcd1 & -0.71 & -0.72 & -0.94 & -0.94 & -0.44 & 0.00 & -0.20 & 0.06 & 1.18 & 1.43 & 1.05 & 1.98 & 1.07 \\
\hline $\mathrm{Cd} 274$ & -0.98 & -1.18 & 1.31 & -1.58 & -0.60 & 0.36 & -1.24 & 0.00 & 0.36 & -1.03 & 0.73 & 1.30 & 0.54 \\
\hline Tigit & -1.08 & -0.94 & 0.51 & -0.19 & -0.09 & 0.00 & 0.17 & 0.69 & -1.50 & -1.33 & 1.43 & 1.35 & 1.12 \\
\hline Havrc2 & 0.00 & -0.26 & -0.37 & -0.83 & -0.28 & 0.34 & -0.46 & -0.04 & 1.45 & 0.84 & 2.25 & 1.85 & 1.45 \\
\hline lag3 & -1.69 & -1.53 & -0.12 & -1.11 & -0.54 & 0.00 & 0.13 & 0.35 & 0.04 & -0.29 & 1.56 & 1.18 & 1.13 \\
\hline
\end{tabular}

